\title{
Dissection and reporting of the organs of the female genital tract
}

\author{
M K Heatley
}

Correspondence to: Mark K Heatley, Department of Histopathology, St James' University Hospital, Beckett Street, Leeds, West Yorkshire LS9 7TF, UK

Accepted 15 August 2007 Published Online First

7 September 2007
The aim of this article is to provide as comprehensive a review as possible of the techniques in use in dissecting and sampling the major specimens encountered in gynaecological practice, whether these have originated from gynaecological oncologists or from gynaecologists who specialise in nonmalignant conditions. A brief description of relevant histology is provided where considered necessary for completeness.

Where possible I have listed material in boxes rather than providing it as free text in order to save space and in the hope that these lists will double as checklists when dissecting and describing these specimens or finalising the report for the clinician. Obviously no list can be exhaustive and it goes without saying that any temptation to pigeonhole features of a given specimen into the necessarily limited series of options included should be resisted. Common tumour types (eg, adenocarcinoma, transitional cell carcinoma and squamous cell carcinomas), and metastases, melanoma, lymphomas and leukaemias, may occur at any site and have been omitted from these checklists to save space. Finally, I have tried to avoid duplicating material provided in other classification systems unless they have interesting associated pathological feature, an obvious example being the association between clear cell carcinoma of the vagina and diethylstilboestrol (DES) exposure in utero.

\section{LYMPH NODES}

It may seem odd that a paper dealing with the female genital organs should begin with an account of how lymph nodes should be handled, but it is worth describing it at this point as these specimens may be obtained either as therapeutic lymphadenectomy specimens or as part of a sampling procedure for cancers at any of the sites described below and the comments are therefore applicable to all these situations.

The TNM system specifies that ordinarily six lymph nodes are recovered from an inguinal and 10 from a pelvic lymphadenectomy, but intriguingly the failure to achieve the number does not alter the nodal staging. ${ }^{1}$ It is preferable that the surgeon submits the nodes from each group he wishes to have assessed separately, as it is often impossible to do this reliably once the anatomical landmarks have been lost when the tissue is removed from the body. Large lymph nodes may need to be sectioned to fit in a cassette, and more than one cassette may need to be used, although several small nodes may be processed intact together in a single cassette. A record should be made of which node goes in which cassette (eg, first node in cassette A, second and third nodes in cassette B, and so on). Every lymph node is examined in its entirety unless obviously replaced by tumour when only one section need be taken providing one is confident that any pericapsular spread has been included in the section.

In the report, the number of lymph nodes recovered at each site, the number involved and a record of whether there are extranodal deposits or evidence of extracapsular spread is included.

It has been my practice for many years to submit all tissue including that which appears to be macroscopically fat for histology. Whilst this undoubtedly increases the lymph node count as fat replaced nodes may be macroscopically indistinguishable from fat, I have never located tumour in these sections.

\section{VAGINA}

Vaginas themselves are rare specimens, as surgeons are reluctant to perform vaginectomies, and when encountered as a complete organ they are usually part of an exenteration specimen, the dissection of which is described in the section below.

The site at which the tumour is located should be recorded (box 1), but one is usually dependent on the clinician for this information, as most specimens from the vagina are biopsies. Some tumours occur in association with pre-existing conditions (eg, clear cell carcinomas associated with exposure of the patient to DES in utero are an iatrogenic curiosity). (DES is incidentally associated with an increased risk of high-grade cervical intraepithelial neoplasia (CIN) lesions. ${ }^{2}$ ) Endometrioid carcinoma related to endometriosis and mucinous carcinomas related to endocervicosis are described.

\section{EXENTERATION}

These specimens are usually received fixed, but ideally the bladder and/or rectum should be inflated with formalin in the fresh state and cotton-wool soaked in formalin should be introduced into the vagina. Once fixed, the specimen is bisected in the sagittal plane, and both cut surfaces photographed. Essentially the description of any lesion and the information included in the report follows that for each organ identified in the specimen, as detailed below. It is also important that in addition to the dimensions of the tumour, the distances to key surfaces or resection margins of the overall exenteration specimen, which are not an integral part of any included organ, are measured and documented. Ideally the site from which any blocks originate should be marked on a photograph. A note should also be made of any fistulae or radiation changes. 
Box 1: Information to be included in the report of a vagina specimen

- Nature of specimen: vaginectomy, vagina as part of an exenteration specimen

- Dimensions: length, width, thickness of wall

- Site of lesion: anterior/posterior; upper, middle or lower third

- Appearance of tumour: polypoid, ulcerated, pigmented (eg, in melanoma)

- Dimensions of tumour and distance to resection margins

- Histological type

- Tumour grade

- Associated intraepithelial neoplasias and their grades/vaginal intraepithelial neoplasia, cervical intraepithelial neoplasia, vulval intraepithelial neoplasia, correlation with cytological history may be necessary)

Box 2: Information to be included in the report of a vulval resection

- Specimen type: simple, subcutaneous, radical

- Overall dimensions of the specimen

- Tissues included (skin, vagina, anus, subcutaneous tissue, lymph nodes) and their dimensions

- Site of tumour: left or right, anterior or posterior, labial (minora/majora) lateral or crossing midline, periurethral, perivaginal, perianal, relation to Bartholin's glands

- Appearance of tumour: warty, verrucous, papillary, ulcerated

- Size of tumour: measured in its two maximal horizontal dimensions and the maximum depth of invasion if possible

- Appearance of tissues adjacent to the tumour: atrophy, keratosis, ulceration

- Resection margins of tumour: vaginal, urethral, anorectal, skin - side which is closest to the tumour; the distance to the closest of these should be measured

- Invasion of structures adjacent to the tumour

- Type of tumour: as well as squamous and adenocarcinoma, basaloid, warty, verrucous, basal cell carcinoma, malignant melanoma, and tumours of skin adnexae and Bartholin's gland may occur

- Grade of tumour: well, moderate, poor

- Lymphovascular invasion: present, absent

- Surface dimension and depth of tumour invasion (depth of invasion is defined as the distance between the epithelial/ dermal interface of the most superficial dermal papilla and the deepest point of invasion; if it is not possible to give a depth of invasion (eg, due to ulceration of the epithelium or improper orientation it may be helpful to the clinician to provide a thickness of the tumour that is visible)

- Depth of tumour-free dermis, fat, etc

- Dysplasia/intraepithelial neoplasia: presence/absence, grade:

- Dysplasia in lower third: mild dysplasia vulval intraepithelial neoplasia (VIN) I, vaginal intraepithelial neoplasia (VaIN) I

- Dysplasia in lower two-thirds: moderate dysplasia VIN II, ValN II

- Dysplasia in full thickness: severe dysplasia VIN III, VaIN III

- Associated features in the adjacent non-malignant epidermis: human-papillomavirus-associated features, lichen sclerosus/ lichen planus, squamous hyperplasia

\section{VULVA}

\section{For malignant disease}

The type of specimen should be recorded. It is useful to photograph and ink the margins of these specimens and I follow the international maritime convention by painting the left side red and the right green because it is easy to remember. The dimensions of the specimen overall and then of all the included tissues (skin, vagina, anus and subcutaneous tissue) should be measured. The site, size and appearance of the tumour and the distance to the relevant resection margins are recorded (box 2).

\section{Blocks}

A slice is made through the specimen to include the deepest area of invasion of the tumour and adjacent margins. It is often helpful to include the closest lateral and deep margin in these blocks (fig 1, a-c), if necessary dividing the blocks to ensure they fit into the cassette, although in large specimens this is often not possible and these will need to be separately sampled. I prefer to do this circumferentially (fig 1, b), and embed the surface that is the true limit downward so that it is represented in the first paraffin section. Any other resection margins (vaginal, urethral and anal) should also be sampled (fig 1, c), and again depending on the proximity of the tumour this may be circumferential or longitudinal. Peritumoural skin preferably from all four quadrants should also be sampled to exclude or diagnose lichen sclerosus or other dermatoses (fig 1, d). It is worth encouraging the surgeon to put a portion of urinary catheter in the urethra to assist in its identification and preserve its patency.

I identify and retrieve lymph nodes from any attached fatty tissue and from the separately submitted lymph node groups. These are handled as for any other site. Xerography has been advocated as a means of facilitating their identification. ${ }^{3}$

\section{Report}

In the report, specific features that should be included are listed in box 2. The depth of tumour invasion and amount of tumourfree dermis should be measured microscopically using the vernier scale or eyepiece graticule. The International Federation of Gynecology and Obstetrics (FIGO) classifies tumours under $20 \mathrm{~mm}$ in diameter and less than $1 \mathrm{~mm}$ in depth as stage 1a1. The importance of this is that many

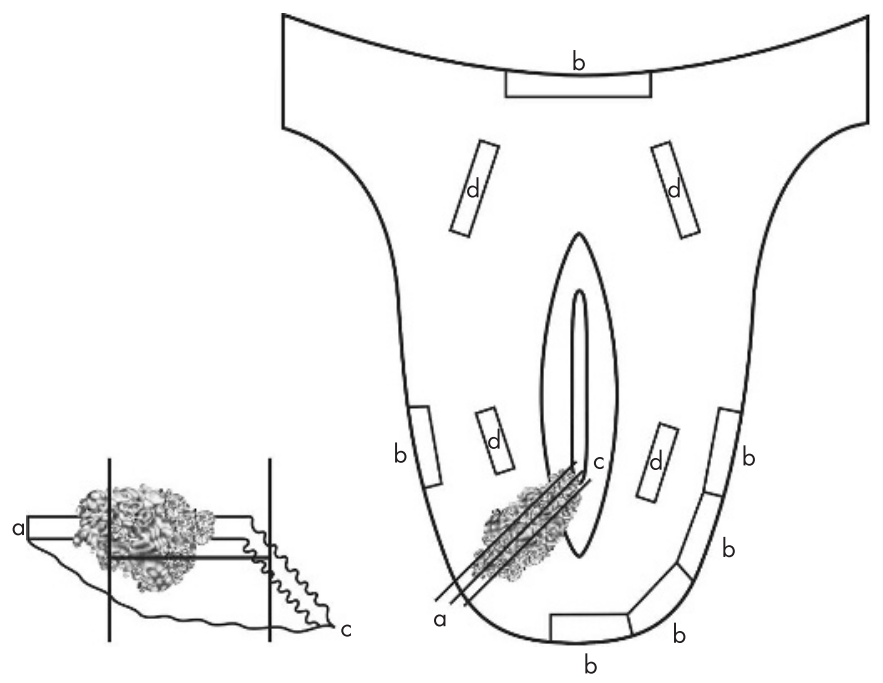

Figure 1 Diagram showing blocking plan for vulvectomy specimens. 
surgeons will undertake a groin lymph node dissection if these dimensions are exceeded. If the surface of the tumour is ulcerated so that a depth cannot be provided, I provide a thickness instead, measuring from the surface of the specimen to the deepest point of invasion. ${ }^{4}$

The report should also include details of the presence and grade of dysplasia (the term preferred by dermatologists)/vulval intraepithelial neoplasia (VIN, the term preferred by gynaecologists). I mention both systems in my report because these may be submitted by either dermatologists or gynaecologists, both of whom may be involved in the care of the patient at different times in the natural history of the disease, even if the patient is not being managed in a specialist vulval clinic.

\section{Vulva: skin removed for intraepithelial neoplasia}

I photograph, measure and (if they can be orientated) paint these as described above, and section them at $3 \mathrm{~mm}$ intervals perpendicular to the mucosal/epidermal surface, marking the site of origin of each slice on the photograph. They are all embedded with the left-hand side of each section in turn facing downward and the obverse surface marked, usually with a dot of red ink to assist the histotechnologist with orientation. As a result, the first section from each block is $3 \mathrm{~mm}$ apart. I prefer to put each slice in an individual cassette, but if there are going to be a lot I double up provided the identity of each slice can be determined by simply looking at their image on the photographic record.

The main features to include in the report are the presence, extent (in terms of the number of blocks involved by VIN) and grade of any intraepithelial neoplasia (VIN I, II or III), and adequacy of excision. If this is close, I measure it. Remember, Paget disease may extend beyond the clinically obvious lesion and consequently these epidermal edges are often involved.

Other comments to include are the presence or absence of invasive malignancy or dermatoses.

\section{Vulval and vaginal biopsies (punch and wedge)}

The number and dimension of each biopsy are recorded usually by the histotechnologist, although wedge biopsies may require medical input and I treat these as described above. At least three and preferably six levels should be cut off each block. I do not routinely ask for a fungal stain, though this may be helpful in a non-specific inflammatory condition. Remember that these specimens are obtained for a variety of dermatological conditions and not just the exclusion or diagnosis of malignant and premalignant disease.

\section{CERVIX}

\section{Cervical polyps}

Unless very large, when a longitudinal slice through the specimen including the base of the stalk is representative, all the tissue is embedded. Although it is said that endocervical polyps may give rise to changes that are confused with borderline nuclear change or dyskaryosis on cervical cytology, they may be associated with a genuine CIN lesion in the adjacent cervix (in $2.7 \%$ (95\% confidence interval (CI) $0.5 \%$ to $13.8 \%$ ) of cases in a personal series).

In the report, the precise origin of the tissue (endocervical, endometrial, mixed (ie, of probable lower segment origin)) and the diagnosis are given. The presence or absence of invasive malignancy or any other abnormalities should also be described.

\section{Manchester repair}

These are now rare, but I would handle them as the cervix from a hysterectomy for benign disease as described below.

\section{Box 3: Histological assessment of cervical punch biopsies}

- Presence/absence of ectocervical squamous epithelium, endocervical glandular epithelium and deeper tissue (ie, endocervical crypts and stroma)

- Presence/absence of dysplasia: squamous CIN III, II or I; epithelial abnormality of uncertain significance; glandular dysplasia - cervical intraepithelial glandular neoplasia/ adenocarcinoma in situ

- Evidence of wart virus infection

- Presence/absence of invasive malignancies

\section{Cervical punch biopsy}

The macroscopic description, which is usually limited to a dimension, can be left to the histotechnology staff, though large biopsies such as a wedge specimen may require sectioning to fit into a cassette. Eosin-stained formalin does not assist in orientating cervical biopsies in my experience, and technologists have complained that it hampers distinguishing stroma and epithelium when orientating the specimen. They have found it helpful to receive the biopsy placed stromal side down on filter paper, even when the specimen detached from the paper, because it retains a flat base. ${ }^{5} 6$

We routinely examine six histological levels from each block. The greatest yield is obtained in the first three sections, with examination of the further three levels resulting in an increase in the grade of CIN in about $10 \%$ of cases. Arguably, therefore, fewer levels need be cut if local arrangements allow the pathologist to be confident that discrepancies between the biopsy and highest grade of dyskaryosis on the previous smear can be reliably identified.

The content of the report is determined by the National Health Services Cervical Screening Program ${ }^{6}$ and is summarised in box 3 .

All grades of CIN, including ungradable CIN and epithelial abnormality of uncertain significance, should be described, starting with the highest. The presence of viral features such as koilocytosis, warty features or a flat condyloma is mentioned after the CIN.

An invasive malignancy may be encountered, and estimates of type and grade are possible, though it must be stressed to the clinician verbally or in writing that the biopsy may be nonrepresentative and that the adequacy of excision cannot usually be predicted on this type of specimen. These specimens are not usually sufficiently well orientated to allow a reliable assessment of the depth of invasion and further, ulceration of the surface epithelium reduces this measurement's reliability; however, an overall approximate estimation of the dimension may be useful, providing it is made clear verbally or in the report that this measurement is for guidance and may not be reliable. ${ }^{6}$

Distinctions should be made between those specimens that fail to explain the cytological and colposcopical findings because they are technically inadequate, and those that are adequate but fail to account for the referral findings. ${ }^{6}$ 
Box 4: Information to be included in the report of a cervical loop excision/cone biopsy specimen

Cervical intraepithelial neoplasia (CIN):

- The specimen is measured and the number of blocks taken recorded

- All grades present are noted, the highest should be recorded first

- Are both lips are involved?

- Is CIN confined to the endocervical canal?

- Number of blocks containing CIN

- Involvement of endocervical crypts if present

- Presence of CIN at specimen edges: ecto, endocervical and deep lateral edges

- Presence of endocervical epithelium at the end of the canal

- Presence/absence of invasion

- (If three or more blocks are involved the tumour may be more than $7 \mathrm{~mm}$ across)

- Evidence of wart virus infection

Glandular dysplasia/intraepithelial neoplasia:

- Grade high/low

- Extent

- Completeness of excision

- The UK National guidelines ${ }^{6}$ comment that a note should be included in the report that glandular lesions of the cervix have a high risk of multifocality and residual disease in the form of skip lesions may persist up the canal; similarly, a note should be included that the presence of $\mathrm{CIN}$ at a specimen limit prohibits a diagnosis of microinvasive carcinoma

\section{Loop excision specimen/cone}

These are usually performed when confirming a cytological or colposcopic diagnosis of squamous CIN, though they are increasingly performed for cervical intraepithelial glandular neoplasia (CIGN), to excise an ectropion, and rarely to diagnose and quantify a known clinical or colposcopic invasive cancer.

\section{Cone and large loop excision specimens of cervix}

These two specimen types are handled essentially in the same way. The report should indicate whether the specimen was received in more than one piece, and which blocks originated from which piece of tissue. The tissue may be painted with Indian ink and rinsed with acetic acid to ensure the ink stays on the tissue to denote the specimen edges, although diathermy artefact, if severe, may fulfil this role in some large loop specimens. Some pathologists use different colours to mark anterior and posterior surfaces, but I find the ink often runs, causing confusion. I do not encourage clinicians to pin the pieces making up a fragmented specimen on corkboard, as I find this damages the epithelial surface.

A permanent photographic record of the specimen should be made using the digital or Polaroid camera. ${ }^{6}$ Loop excisions should be sectioned transversely at regular intervals. Use of a pre-calibrated cutting board facilitates this, providing the tissue is well fixed and a sharp knife such as a skin graft blade is used. The cutting board I use is prefixed at $3 \mathrm{~mm}$ intervals. Each slice is turned to the right and embedded in individual cassettes, and as a result the tissue is examined at equal intervals throughout.

It is useful to standardise the sequence with which blocks are processed. If the clinician has orientated the specimen, I label

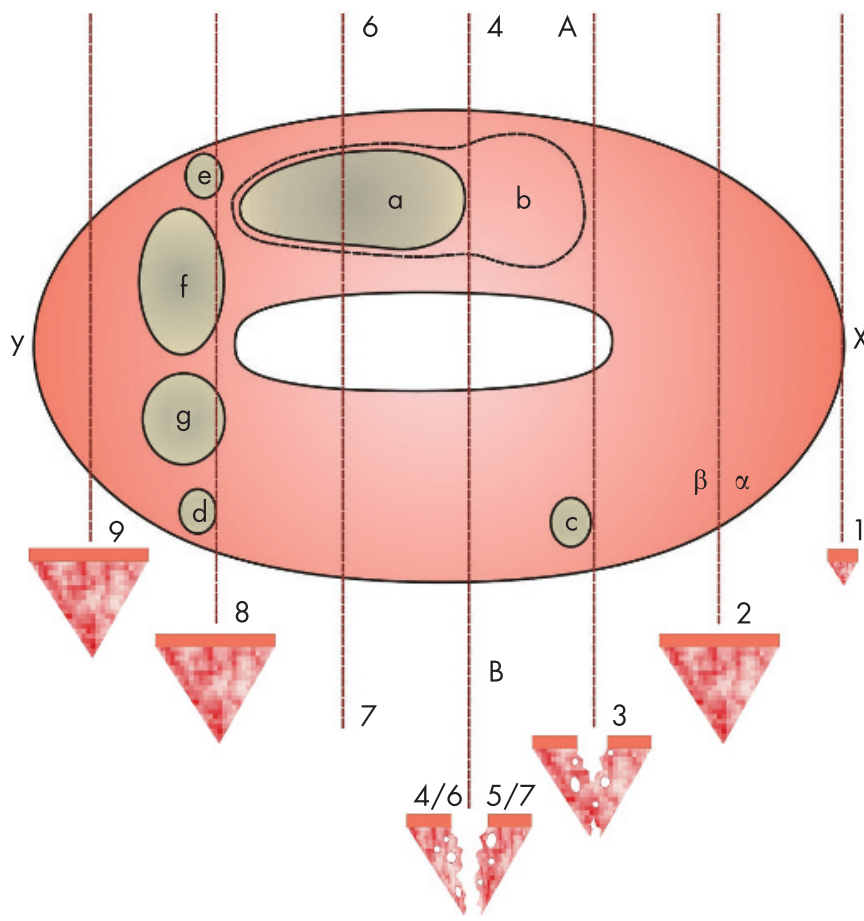

Figure 2 Diagram showing blocking system and its rational for loop and cone biopsy specimens.

the blocks from the extreme left of the specimen (ie, surface X) moving toward the right, and number those from the anterior lip before the posterior lip (fig 2). I mark the surface of the block opposite to the one I wish to have embedded downward, and thus sectioned first, with red ink just in case the tissue should turn in the processing cassette before or during opening. I prefer to put each piece into a separate cassette and mark where they have come from on a photograph of the specimen, and only divide slices if they are too big to fit into the cassette, as introducing a metal instrument into the canal damages the epithelium, especially the columnar epithelium. If it is necessary to do this, I squeeze the transverse aspects of the tissue slice and make the canal pout so I can insert the knife without it making contact with and damaging the epithelium. Over the years, I have found that it is a good policy to minimise any manipulation of these specimens, as the epithelium, particularly if there is extensive CIN III, may be very friable and excessive handling may result in its being denuded. The system described above is illustrated in the diagram (fig 2) where the initial slices (1 and 2) show ectocervix, but as the slices are progressively taken there is a gradual emergence of the columnar epithelium in the crypts around the canal (3) and then the canal itself including the squamocolumnar junction (4-7). The transverse (fig 2, A and B) and first lateral edges (fig 2, X) of the specimen are examined. Some pathologists turn the first block through 180 deg before embedding it, arguing that by doing so they get a greater profile of tissue but I would suggest that the resulting section (alpha) is merely a mirror image of the section (beta) that is cut from the block that follows and that unless this first block is routinely turned through 180 deg re-embedded and a further section (representing the edge denoted by $\mathrm{X}$ in fig 2 ) is cut, the first $3 \mathrm{~mm}$ of tissue are left unrepresented histologically.

If the cone is more than $25 \mathrm{~mm}$ long apical blocks are taken and embedded in the first cassette(s). 
All the tissue should be submitted for histology.

I resist routinely examining multiple levels, as I believe that it is uneconomic in technical and medical time and as experience has shown that should it be necessary to invert the block to examine the obverse side, it can cause technical difficulties if excessive levels were taken initially. Should there be a discrepancy between the previous cytological or the colposcopic diagnoses and the histological features, or if the section, particularly the squamocolumnar junction, is incomplete, I examine a single deeper level because in 6\% $(95 \%$ CI 3.5\% to $10.2 \%$ ) of cases this has resulted in a significant increase in the grade of CIN identified and in $2.5 \%$ (95\% CI $1.1 \%$ to $5.7 \%$ ) of cases it has allowed its identification for the first time.

Inverting the last block (fig 2, section 9) may be necessary to demonstrate involvement of lateral edge Y (some pathologists argue it is unnecessary to do this as the presence of CIN $3 \mathrm{~mm}$ from any edge (eg, in section 9) has the same prognostic significance as if definite margin involvement is encountered). If CIN I is present at such a margin, recent work suggests there is no increased risk of recurrent disease over patients with clear margins. $^{8}$

If stromal invasion is noted in two consecutive blocks (eg, fig2, sections 4 and 6) I cut further levels from these blocks, and I turn the block preceding the first of these since the largest tumour profile may be in the preceding slice. Thus inverting block 3 and sectioning into it may provide the best assessment of the cross-sectional tumour size in tumour b (fig 2).

\section{Report}

The presence of CIN should be noted and all grades present recorded. I usually make a note of which blocks are involved in brackets after the grade of CIN, as it is useful if I need to demonstrate this in a hurry at a multidisciplinary meeting, and also because it gives a semiquantitative indication of the extent of the disease. I also record whether both lips are involved, if disease is confined to the endocervical canal, as this may not be visible colposcopically, or if it involves the endocervical crypts. . $^{9-12}$ The prognostic importance of these criteria may simply be that they provide an indication of the overall size of the area of abnormality. ${ }^{13}{ }^{14}$ The condition of the specimen edges and the presence of endocervical or squamous epithelium at the end of the canal is recorded systematically. The presence of glandular dysplasia/intraepithelial neoplasia, which in the UK is graded as low or high grade, is recorded along similar lines (see box 4).

Tumours that are visible to the naked eye are staged as $1 b,{ }^{1}$ but, if microscopic, the tumour should be measured using an eyepiece graticule or the vernier stage on the side of the microscope ${ }^{15}$ to establish if it exceeds the criteria for stage 1a1 tumours $(7 \mathrm{~mm}$ across by $3 \mathrm{~mm}$ deep, below originating epithelium in the crypt or intact surface), as it may warrant aggressive surgical treatment. The dimensions should be measured on the section showing the greatest profile. This provides two of the three dimensions cited (ie, one transverse dimension across the section and the depth). Even if the tumours are $<7 \mathrm{~mm}$ across $\times 3 \mathrm{~mm}$ deep, the third dimension may exceed $7 \mathrm{~mm}$, and Burghardt, who developed the system of examining parallel sections, advocated multiplying the greatest dimension by 1.5 to arrive at this "third dimension". ${ }^{16}$ Traditionally British pathologists have sought to establish this third dimension by multiplying the number of involved slices by their thickness. Thus in tumour b (fig 2), where three $3 \mathrm{~mm}$ slices are involved, this dimension is up to $9 \mathrm{~mm}$, whereas tumour a with two slices involved is no more than $6 \mathrm{~mm}$ thick. To ensure the third dimension of the tumour is not underestimated, I turn the block preceding the block from which the section first showing tumour was cut, through $180 \mathrm{deg}$ to exclude invasive tumour in it. In tumour a, this is slice 3 (fig 2) and it is not involved, confirming that it involves only two slices, and, as each of them is $3 \mathrm{~mm}$ thick, it is less than $6 \mathrm{~mm}$ (ie, stage 1a1).

In contrast, with respect to tumour $b$ in fig 2 , the initial sections would show tumour in slices 4 and 6 , which are in continuity but not in section 3 . Turning section 3 reveals an invasive component suggesting invasion over three slices (up to $9 \mathrm{~mm}$, and indeed the largest cross-sectional dimensions would be located as a result of this process). This method probably overestimates the third dimensions in some cases, but is justified on the basis that tumour is better over treated than under treated.

The consequence of this method of arriving at this third dimension is that the only person who can assess what it is, is the person who cut the case, as only he/she can be confident as to whether the blocks were cut at 2, 3 or $4 \mathrm{~mm}$ intervals and if they were of equal thickness. Thus the person cutting the case should usually be deferred to when invasive tumour involving more than one contiguous slice is encountered; this issue may cause problems especially when cancer centre pathologists are reviewing the work of others. (Note: microscopic tumour invasion and early stromal invasion are descriptive terms that are no longer used to describe tumours that are less than $1 \mathrm{~mm}$ deep $\left.^{4}\right)$. Another area of controversy is when several small foci of microinvasion, none of which is more than $7 \times 7 \times 3 \mathrm{~mm}$ deep but which are separated by more than $7 \mathrm{~mm}$, are encountered, as in foci $\mathrm{c}$ and $\mathrm{d}$ in fig 2 . We will assume that foci $\mathrm{d}$ and $\mathrm{e}$ in the same slice are also separated by more than $7 \mathrm{~mm}$ of noninvasive tissue. The FIGO and TNM classifications give no advice as to how best to proceed in this scenario. In my view it is illogical to stage widely separated foci that may be confined to one or two cells as being of stage $1 \mathrm{~b}$ and presumably therefore warranting radical surgery, whereas two foci each $3.4 \mathrm{~mm}$ across (fig 2 , $\mathrm{f}$ and $\mathrm{g}$ ) separated by less than $0.1 \mathrm{~mm}$ of tissue and thus occupying a lateral dimension of less than $7 \mathrm{~mm}$ are stage $1 \mathrm{a} 1$ and do not warrant such treatment despite having a greater overall volume. Burghardt, in his paper, describes adding the volume of such tumours together, and indeed his prognostic data are based on this strategy. ${ }^{17}$ In my experience, most clinicians appreciate this problem and judge each case on its merits after discussion with the patient (box 4).

\section{Deep resection edges (the so-called top hat)}

Large specimens may warrant being treated as above but on occasion it may be best to place an inked orientation mark on the specimens to ensure the distal resection margin is sectioned first and process them intact. In this situation, consideration should be given to ordering levels at cut up. If this option is taken, a photograph must be available that should be marked to indicate how the specimen was orientated.

Invasive tumours are typed using the World Health Organization (WHO) system, which may be supplemented by consulting the International Society of Gynaecological Pathologists' modification. ${ }^{18}$

Other useful information is the presence or absence of lymphatic/vascular invasion; although this does not alter the stage of the lesion some surgeons will opt for more radical surgery if it is extensive or if the primary tumour shows adenocarcinomatous differentiation. Some pathologists also comment as to whether the border of the tumour is confluent or infiltrative. 
The description for the dissection of hysterectomy specimens in patients with CIN or invasive cervical tumours is included in the section dealing with hysterectomies below.

\section{Tissue trauma}

Opening cone biopsy and loop excision specimens may damage the epithelium lining the endocervical canal and may also result in underestimating the dimensions of a peripherally placed invasive tumour; this practice and attempts at "clock facing" an intact specimen should be discouraged. ${ }^{19}$

\section{Box 5: Histological assessment of endometrial samples}

- Phase of cycle (proliferative, secretory, menstrual), inactive, atrophic, postmenopausal)

- Inflammation/stromal reaction if present

- Hyperplasia (disordered proliferative endometrium, simple or complex architectural hyperplasia with/without cytological atypia), intraepithelial neoplasia

- Malignancy (endometrial adenocarcinoma should be typed and graded)

- Vascular lymphatic and myometrial invasion if present

\section{Endocervical curettings}

I have not seen a specimen of this type for many years. They should be discouraged, since if malignant endocervical pathology is present it may render attempts to assess the presence and depth of stromal invasion impossible. Their value therefore seems to be confined to saying whether or not abnormal epithelium is present and even then it may not be possible to grade $\mathrm{it}^{20}$; this information can be extracted by a cytopathologist from a properly handled cytology specimen.

\section{TRANSCERVICAL ENDOMETRIAL RESECTIONS}

The tissue must be weighed, as this may have prognostic significance for the patient. ${ }^{21}$ Since these can be abundant specimens it may be reasonable to sample the material rather than submitting it in total. I reviewed the follow-up of over 200 such specimens that had been submitted in total, and none ( $95 \%$ CI $0 \%$ to $1.9 \%$ ) was associated with a diagnosis of hyperplasia or carcinoma; this is perhaps not surprising since the patients are screened ${ }^{22}$ to ensure they are suitable for such treatment, usually having one or more hysteroscopy and endometrial samplings followed by a prolonged course of medical treatment, such as systematic or local progestogen, before the transcervical resection of the endometrium (TCRE)! Those cases in the literature where invasive carcinoma has first been encountered at TCRE have usually occurred in women whose prior biopsy was obtained with difficulty, was inadequate or was inconclusive, ${ }^{23}$ or where carcinoma was present extensively throughout the tissue making its detection in a sampled specimen likely. ${ }^{24}$ There has been a single case of endometrial intraepithelial neoplasia diagnosed at endometrial resection. ${ }^{25}$

\section{ENDOMETRIAL CURETTINGS AND PIPELLE SPECIMENS}

The volume of tissue should be estimated. This can be done by using a ruler to measure the aggregated sample size, but like many pathologists I prefer to use a semiquantitative method that combines ease of use with an immediate estimate of the amount of tissue one should expect on the slide. If less than one-quarter of the cassette base is occupied by tissue I describe the sample as scanty, and if more than one-quarter is occupied but it can all be accommodated in one cassette I regard it as moderate. Tissue requiring more than one cassette is designated bulky and is weighed. The presence of identifiable polyps and their longest dimension is recorded and an estimate of the proportion of tissue composed of mucus or blood is made. I usually examine all the material histologically.

Points for the histological assessment of endometrial samples are listed in box 5. It may be difficult to give any more precise estimate of the day in the cycle from which the specimen originated than early, mid or late secretory phase if the specimen has not been specially fixed in Bouins or other picric-acid-based fixative. ${ }^{26}$ The maturity of the secretory transformation in glands and stroma is assessed because dyssynchrony may indicate an underlying disturbance in hormone levels or the tissues' response to them. The pathologist should not confine himself to a simple confirmation or exclusion of malignancy because many benign mimics have features that overlap intra-endometrial adenocarcinoma. ${ }^{27}$ If hyperplasia is present, it is worth conveying any suspicion of invasive malignancy to the clinician. ${ }^{28}$

Hyperplasia or malignancy should be considered and specifically excluded in the report if possible, or typed if present. In biopsy material I prefer to describe endometrioid adenocarcinomas as being well, moderately or poorly differentiated, rather than ascribing a FIGO grade to highlight the acknowledged variation (of between $24.6 \%$ and $55 \%$ ) between the grade of endometrial cancer on sampling compared with that in the definitive resection specimen. ${ }^{29}$ FIGO recommend that serous and clear cell carcinomas be graded using the nuclear grade only, ${ }^{30}$ while the WHO regards all such tumours as being of high grade. ${ }^{31}$ I would encourage colleagues to adopt the FIGO practice, as recognising an inconsistent nuclear grade may indicate that the tumour is actually one of the mimics of these high-grade types.

In my experience it is rare to be able to assess the tissue for evidence of lymphatic or vascular permeation, and myometrium is rarely included in samples except in high-grade or high-stage tumours. Care should be taken in assessing endocervical fragments especially if they are involved by tumour, as they may either be the primary source of a cancer that has infiltrated upward into the uterus or secondarily involved by a low-lying endometrial tumour.

Neither endometrial biopsy ${ }^{32}$ nor imaging ${ }^{33}$ alone is sufficient investigation in postmenopausal bleeding, and a combination of biopsy and transvaginal ultrasound or hysteroscopy is advised ${ }^{34}$ ${ }^{36}$ since less than $50 \%$ of the cavity is sampled in most patients, even with dilation and curettage. ${ }^{37} 38$

I comment on the presence of plasma cells, eosinophils, lymphoid follicles and granulomata if I find them, but I am reluctant to exclude endometritis if they are absent because significant pelvic inflammatory disease, including infection with Neisseria gonorrhoeae and Chlamydia trachomatis, may have no histological evidence of endometritis. ${ }^{39}$ If inflammatory cells are absent, a stromal reaction may herald the onset of plasma cell endometritis. ${ }^{40}$

\section{Endometrial polyps}

Ideally these should be removed intact under hysteroscopic control, but in many centres they are removed piecemeal by curettage. The fragments should be weighed and the largest 
Box 6: Information to be included in the report of uterus and cervix specimens

\section{Macroscopic description}

- Weight

- Measurements including length, transverse and anteroposterior dimension

- State of serosa, adhesions, haemosiderin deposits (powder burns), gritty areas suggesting calcification

- Vaginal mucosa

- Cervix:

- Configuration of os slitlike/"parous", circular/"nulliparous"

- Condition of epithelial surfaces (eg, surgical trauma and scarring, polyps, ulcers, "erosions" and large cysts)

Uterus:

- Depth of endometrium

- Presence of polyps, cystic change

- Maximum depth of anterior and posterior myometrium

- Presence/absence of fibroids, site (submucosal, intramural, subserosal), distortion of cavity/cervical canal

- The dimensions of the largest should be recorded along with the presence of necrosis, haemorrhage, calcification

- Presence of previous surgery (eg, scars from Caesarian section, evidence of myomectomy or transcervical resection of the endometrium)

- Other distortion (eg, bicornuate appearance)

- Presence or absence of adnexa

- Length and diameter of Fallopian tubes

- Dimensions and any abnormalities of ovaries

- Presence of cysts, adhesions, powder burns and which adnexa they affect

\section{Microscopic description}

- Cervix:

- Koilocytosis

- Glandular or squamous CIN

- Invasive carcinoma (give dimensions)

- Any other significant abnormalities

- Endometrium:

- Phase of cycle, atrophic, postmenopausal

- Any significant abnormalities (eg, hyperplasia, endometritis)

- Polyps

- Hyperplasias

- Myometrium:

- Adenomyosis

- Confirmation that there is no atypia or coagulative type necrosis in the smooth muscle masses

- Fallopian tubes:

- Any significant abnormalities, including interruptions or the presence of clips or rings

Ovaries:

- Any significant abnormalities such as functional or acquired cysts, endometriosis or neoplasia

measured. The presence of any areas of necrosis should be noted.

Except for very large polyps or those that are obviously fibroid polyps, they should be examined entirely, as they are said to have twice the risk of harbouring hyperplasia and the same risk of developing carcinoma as non-polypoidal endometria, ${ }^{41}$ although these cancers are often of low stage and grade. ${ }^{42} \mathrm{Up}$ to $13 \%$ of usual endometrial polyps, ${ }^{43}$ and nine of 29 patients with polyps showing atypical complex hyperplasia, have been found to have a carcinoma in the adjacent endometrium at hysterectomy. ${ }^{44}$

A recent review dealing with the reporting of endometrial biopsy specimens has been provided. ${ }^{45}$

\section{Myomectomy}

I usually count the number of fibroids submitted and give their range of dimensions. Each should be sectioned and one block from each submitted. ${ }^{46}$ If the fibroid shows any atypical features, additional blocks should be examined. I continue to describe the lesions as fibroids when issuing a report to convey to everyone reading it, particularly the patient if they ask to see the report, that there are no histological concerns about how the lesion will behave, but also include the term leiomyoma to satisfy the fastidious.

\section{HYSTERECTOMY}

Although an argument has been advanced for not examining macroscopically normal hysterectomy specimens histologically, in a series of 139 specimens, one case of CIN $(0.7 \%, 95 \%$ CI $0.1 \%$ to $4.0 \%$ ), a condition that in the UK would warrant follow-up with repeat cytology, ${ }^{47}$ was detected. Most pathologists therefore are reluctant to abandon some histological examination of these specimens. The following technique is primarily designed to be used for specimens in which no or only benign anatomical pathology is expected, and aims to gather the maximum information from the minimum number of blocks, while leaving the specimen in such a condition that it is possible to return to it, to take further meaningful blocks should this be necessary. However, it is readily adaptable for use in malignant conditions. ${ }^{47}$

\section{Preparation of specimen on receipt in laboratory}

If possible, a period of fixation before opening is to be encouraged, as this minimises distortion due to fixation. I am reluctant to inject formalin through the cervical os. I believe that it traumatises the canal and if any intra-epithelial neoplasia is present the abnormal epithelium may be sloughed and damaged, limiting histological assessment. ${ }^{48}$ Junior medical staff and technologists may prefer to mark the anterior midline of the

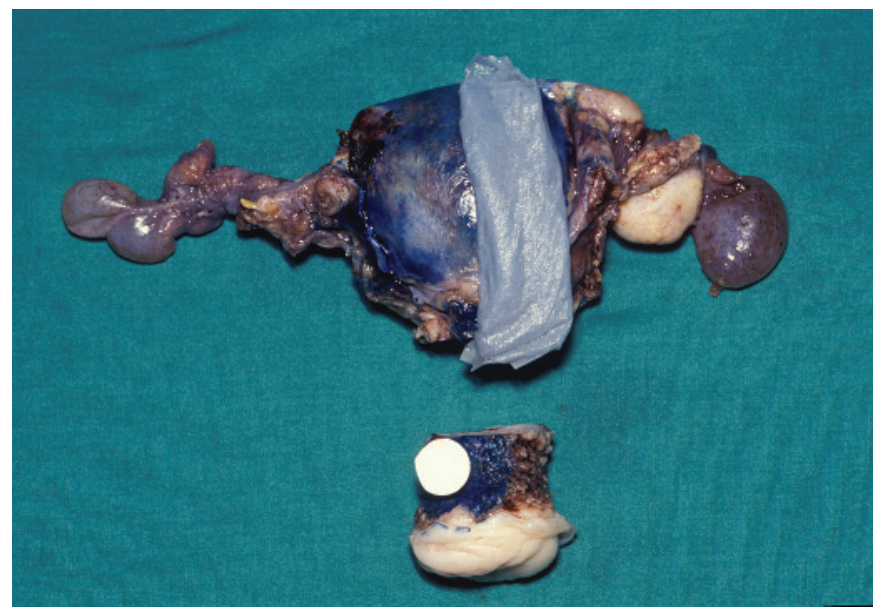

Figure 3 Cut up of "normal" uterus. A length of the cervix is amputated by a transverse cut followed by a single anterior midline incision in the uterus from fundus to the lower resection line. 


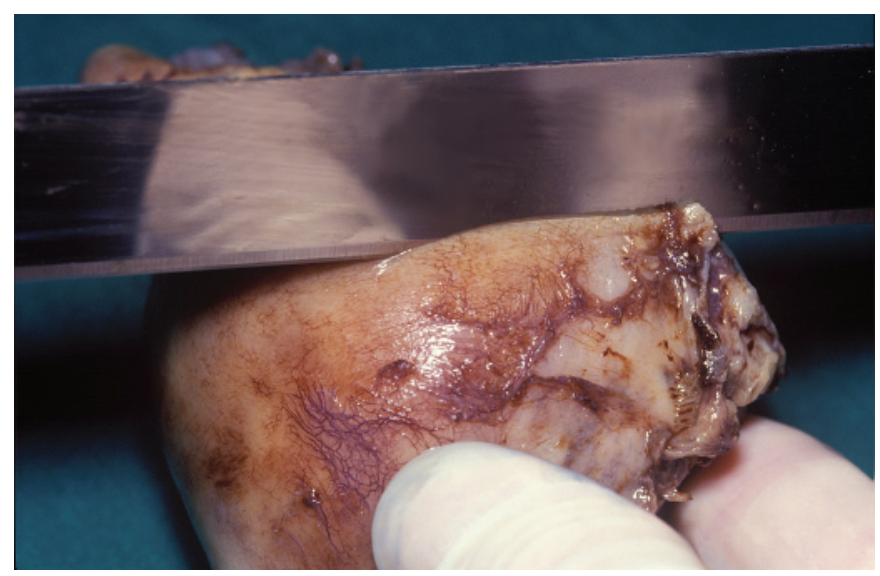

Figure 4 Cut up of normal uterus. A thin sliver of the posterior peritoneal reflection is taken.

specimen with ink, paint or a pin. A $20-25 \mathrm{~mm}$ length of the cervix should be partially or completely amputated by a transverse cut followed by a single anterior midline incision in the uterus from fundus to the lower resection line (fig 3). If the cavity is not exposed, it may be opened by inserting scissors into the lumen of the cavity at the lower uterine segment and cutting upward. Pieces of pre-soaked tissue are placed in the incisions to ensure adequate fixation. If large fibroids are to be incised this is preferably done from the serosa, and these too should be stuffed with paper or cotton wool.

\section{Benign conditions}

Following fixation, the specimen is weighed and measured (box 6). If the uterus was opened by the surgeon or before undergoing partial fixation it may become distorted and only the weight and length can be reliably assessed. The specimen is orientated because the posterior serosal reflection is inferior to the superior reflection and because the ovaries are situated posterior to the Fallopian tubes. In subtotal specimens, I ink the inferior (cervical/lower segment) resection line firstly to mark the limit, but mainly because when it comes to examining the sections it is a convenient reminder that it is a subtotal specimen and not one that has been inadequately sampled or from which slides are missing.

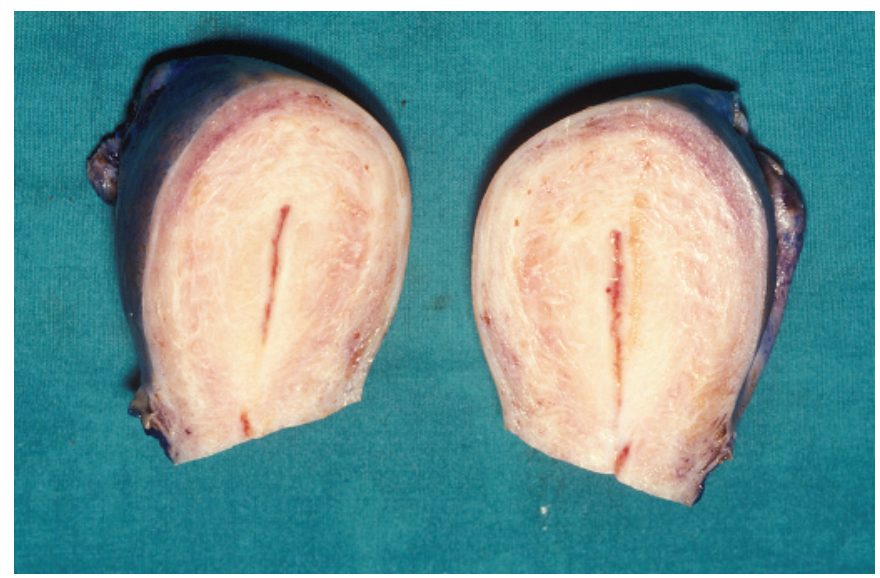

Figure 5 Cut up of normal uterus. Parallel slices of the uterine corpus cut in the sagittal plane.

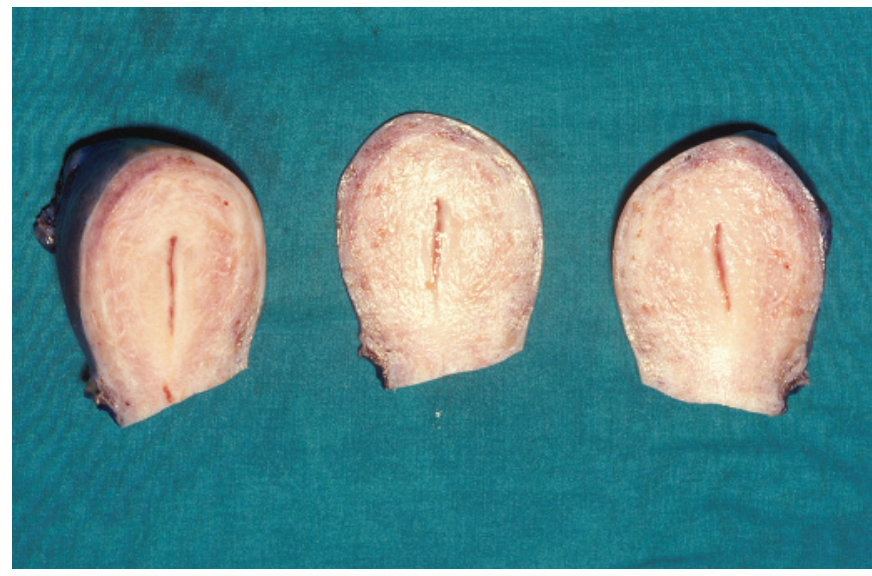

Figure 6 Cut up of normal uterus. Cutting in the sagittal plane until the inferior cavity is no longer visible.

Because of the risk of trauma to the canal epithelium, I would discourage probing of the cervical canal. The prior amputation of the cervix provides a flat base on which it can sit on the bench allowing blocks from anterior and posterior lips of the cervix to be taken in one set of slices using a large knife. I take a full thickness block from both anterior and posterior lip. Histological examination of mid line blocks in the cervix from a hysterectomy specimen in which there is no previous reason to suspect in-situ or invasive neoplasia combines the optimum yield of clinically relevant lesions with an economic blocking policy ${ }^{49}{ }^{50} \mathrm{I}$ also take a thin sliver of the posterior peritoneal reflection as a screening test to exclude endometriosis from patients who have no history or morphological evidence of the condition, embedding it with the posterior lip (fig 4). I feel justified in doing this because although it adds little to the use of resources and manpower in the laboratory in 3\% (95\% CI $1.5 \%$ to $6.1 \%$ ) of hysterectomy specimens from patients with adenomyosis or endometriosis, this was the only site where endometriosis was observed so that its identification may be the only explanation for preoperative or indeed postoperative symptoms. If there was more convincing evidence of endometriosis I would of course block the area formally, along with any adhesions and the left and right parametrial tissue or cornua. Endometriosis may occur in the cornual serosa in $2.9 \%$ of cases $(95 \%$ CI $1.4 \%$ to $5.9 \%)$, although each case was associated with endometriosis in the posterior reflection or adnexa. There may be no need to return

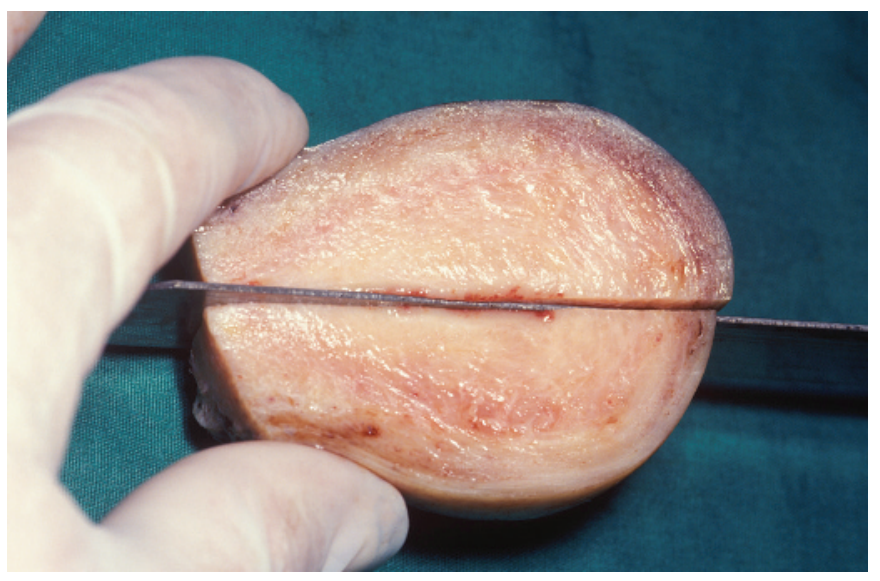

Figure 7 Cut up of normal uterus. Cutting coronally out through the cornua. 


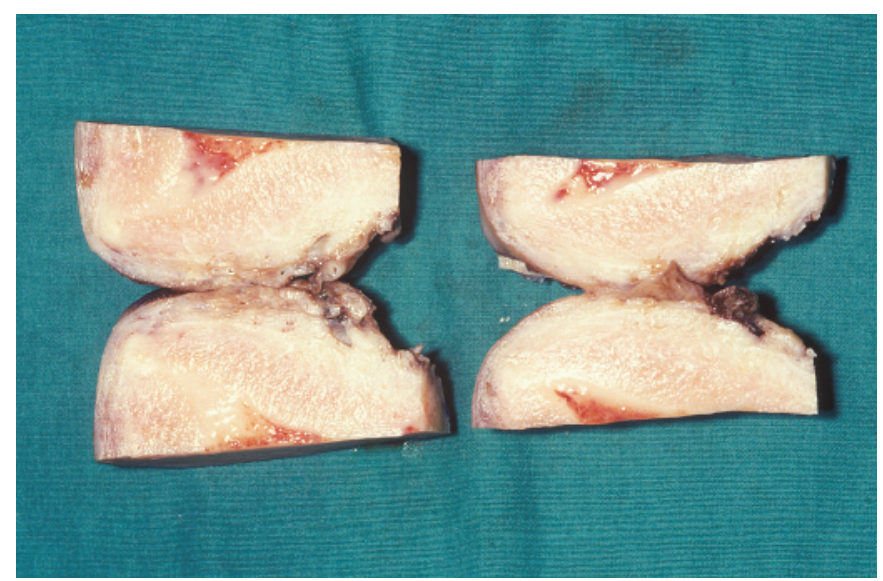

Figure 8 Cut up of normal uterus. Continued cutting through the cornua for macroscopical excludion of polyps or small cancers.

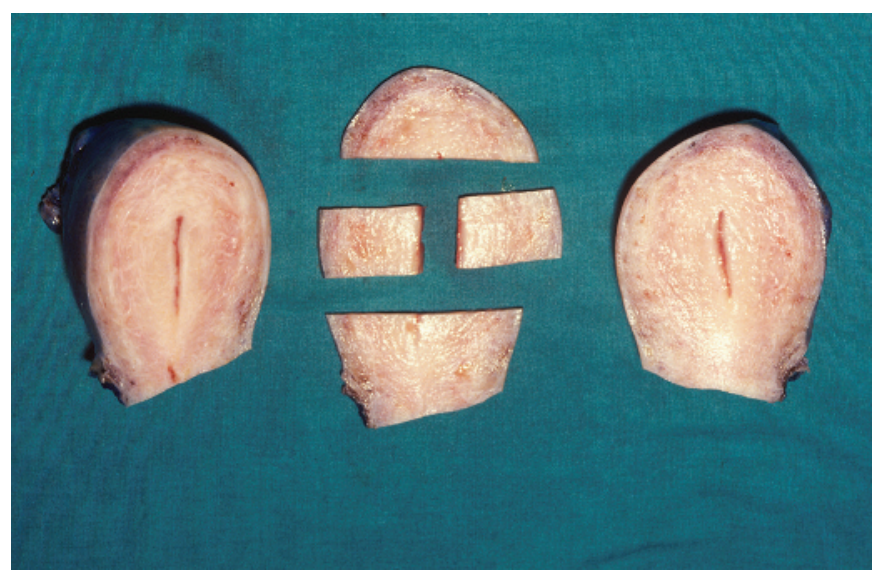

Figure 9 Cut up of normal uterus. One block is taken from each of the anterior and posterior wall, including the endometrium, myometrium and serosa.

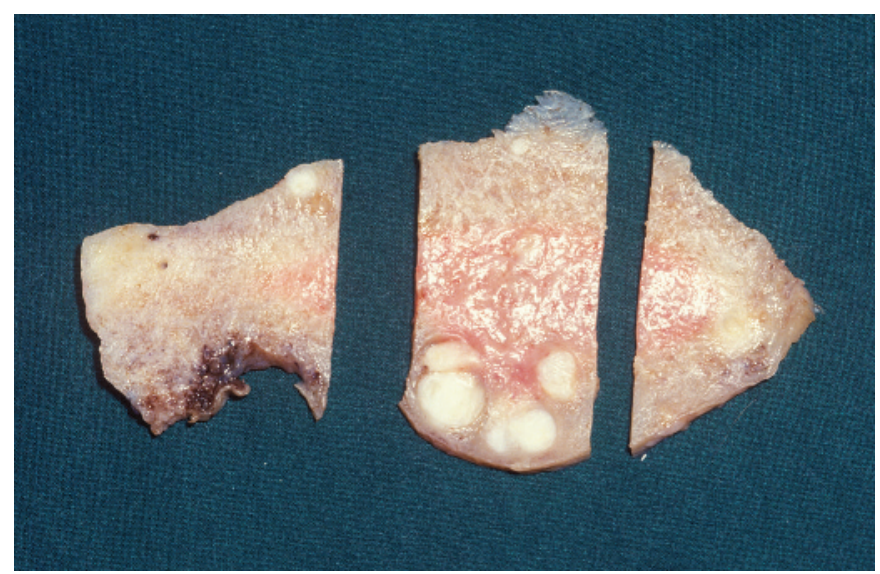

Figure 10 Cut up of normal uterus. Standard endometrial-myometrial blocks with fibroids.

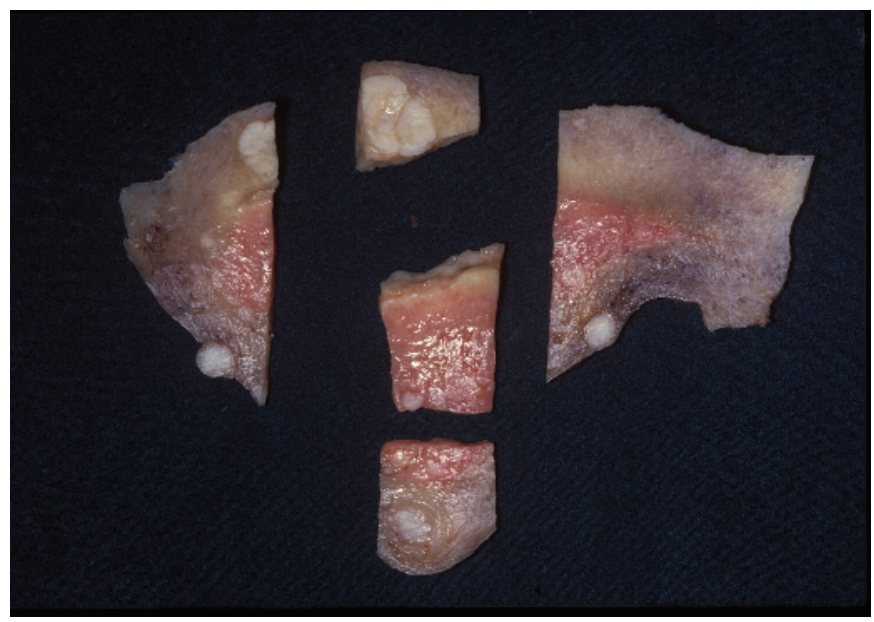

Figure 11 Cut up of normal uterus. Standard endometrial-myometrial blocks with fibroids.

to a specimen in which adenomyosis is unexpectedly encountered histologically to exclude serosal endometriosis ${ }^{20}$ and certainly, in my experience, no patient with adenomyosis has been found to have endometriosis confined to the posterior reflection $(95 \% \mathrm{CI}$ $0 \%$ to $4.2 \%$ ).

I examine parallel slices of the uterine corpus in the sagittal plane (fig 5). I continue cutting in the sagittal plane until the inferior cavity is no longer visible (fig 6) and then cut "coronally" out through the cornua (fig 7) so that I can exclude polyps or small cancers at this point macroscopically (fig 8). In routine cases, I take one block each from the anterior and posterior wall including the endometrium, myometrium and serosa (fig 9). The cornua and lower segment/upper cervical canal are specifically examined histologically, only in cases of hyperplasia or ovarian-acquired cysts.

Blocks from the three largest fibroids including the interface with myometrium are taken from uteri where the fibroids all have a typical macroscopic appearance, ${ }^{3}$ with more extensive sampling of fibroids with an atypical macroscopic appearance such as areas of necrosis, softening, haemorrhage or calcification. It may be possible to include some or all of these in the standard endometrial-myometrial blocks (figs 10 and 11). In cases of suspected neoplasia in a uterine smooth muscle lesion, one block

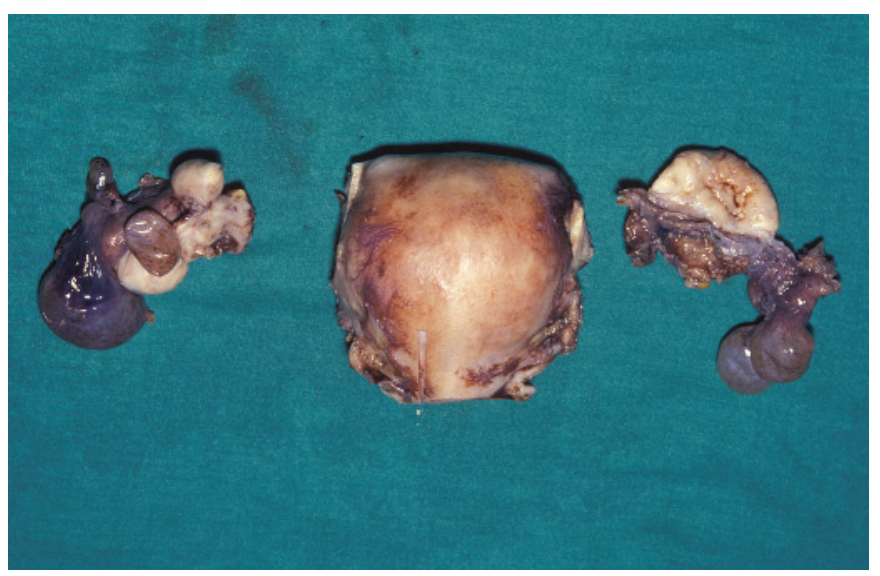

Figure 12 Cut up of normal uterus. The adnexa are detached from the main specimen. 


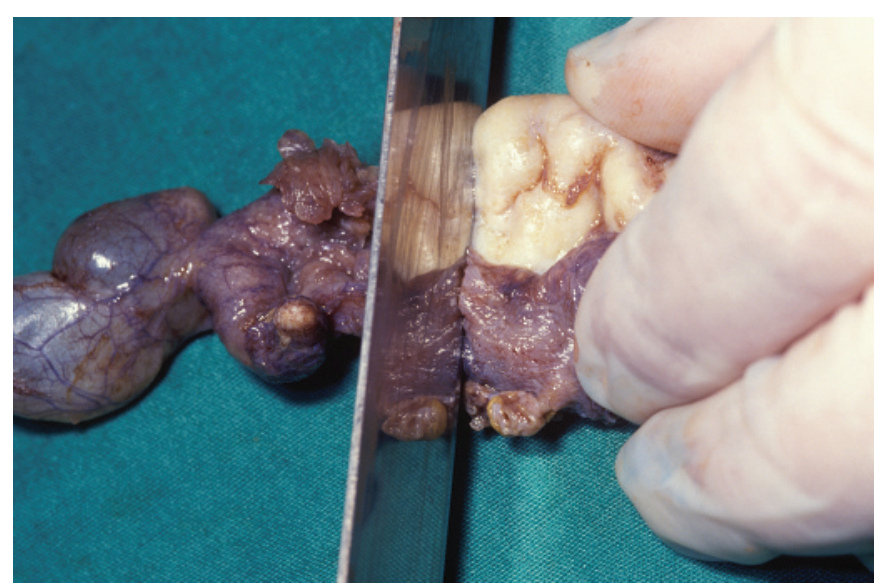

Figure 13 Cut up of normal uterus. The ovaries are sliced at 3-4 mm intervals through the full thickness in the sagittal plane.

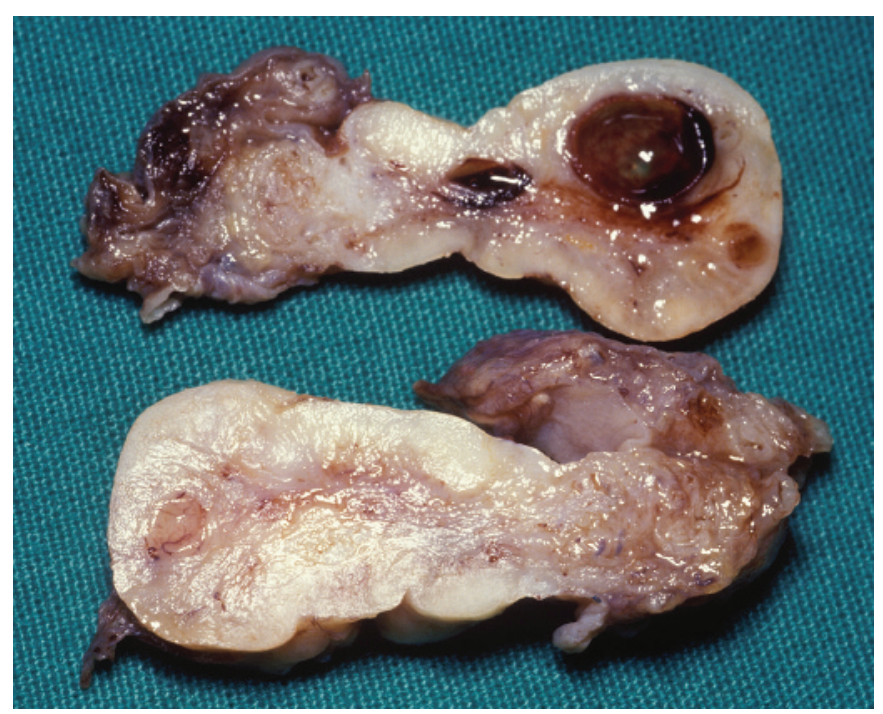

Figure 14 Cut up of normal uterus. Two complete slices are taken from each ovary.

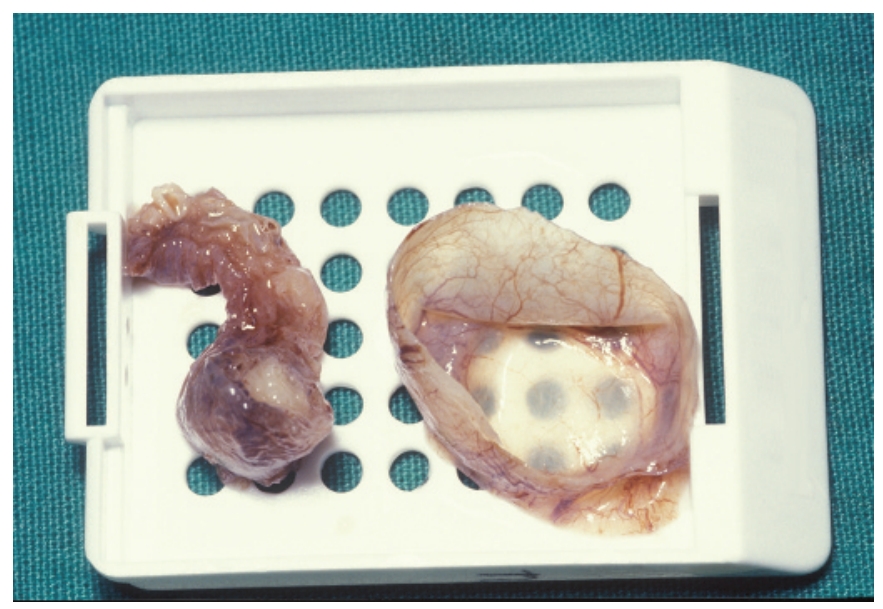

Figure 15 Cut up of normal uterus. Blocks of any other macroscopic abnormalities are taken. for every 1 or $2 \mathrm{~cm}$ of maximum dimension is usually recommended.

I detach the adnexa from the main specimen (fig 12) before opening the endometrial cavity, and slice the ovaries at 3-4 mm intervals through the full thickness in the sagittal plane (fig 13) and take two complete slices from each ovary (fig 14). Further blocks of any other macroscopic abnormalities are taken (fig 15) and, in particular, thick-walled cysts should be sampled at one block per $10 \mathrm{~mm}$ diameter. I prefer to sample the uterine adnexa in continuity if submitted intact, rather than dissecting the tube from the accompanying ovary and soft tissue. In an audit series, 40 of $354(11.3 \%$, 95\% CI $8.4 \%$ to $15.0 \%)$ patients with endometriosis were described as having endometriosis in the peri-adnexal soft tissues; in seven ( $2 \%, 95 \%$ CI $1.0 \%$ to $4.0 \%)$ of these patients it was the only site of endometriosis.

Very occasionally a caesarian hysterectomy is performed either electively because of a malignancy (in which case the specimen is handled according to the relevant section below) or as an emergency following an obstetric complication. The specimen is largely handled following the above protocol, with attention to the presence of any lacerations or incisions, and whether or not they are sutured. Sections of these and the full thickness of the wall, including the placenta and decidua, are recommended. If giant sections are unavailable, it may be necessary to divide the slice into several blocks marking their origin on a photograph or diagram. It may be necessary to refer to a protocol for handling placental and occasionally, unfortunately, fetal specimens.

Specimens removed for malignant conditions are effectively handled as outlined above, but with a more extensive description and sampling to reflect the anatomical position of the tumour.

\section{Hysterectomy for carcinoma of the endometrium}

In the case of endometrial tumours, the exact location within the cavity should be described, though it should be remembered that large lesions might extend over a combination of these sites. Although the dimensions of the tumour are traditionally measured in three dimensions, from a staging perspective the most important dimensions are the depth of macroscopic extension into the myometrium at the point at which the tumour extends closest to the serosal surface and the minimal depth of myometrium unaffected by tumour, as this allows calculation of the percentage of the thickness of the wall that is infiltrated by tumour; this is a key feature of FIGO staging. Involvement of the cervix, cornua, Fallopian tubes and ovaries should be confirmed or excluded. The presence or absence of previous surgery (eg, scars from Caesarian section) may be important as it may provide a point of weakness that facilitates tumour invasion. ${ }^{51}$

In some parts of the world, these specimens are examined peroperatively to guide the surgeon as to the need to undertake lymph node resections. However, at least one study has suggested that this results in a higher grade and stage being provisionally assigned to the tumour than is the case in the final report $(p<0.0001) .{ }^{52}$ This could reflect caution on the part of the pathologist who is anxious to ensure that there is no risk of patients being under-treated on the basis of his/her frozen section opinion. ${ }^{53}$

Blocks are taken to confirm the diagnosis, establish the grade of tumour, especially endometrioid adenocarcinoma, and to establish its stage. Although criteria for grading and staging are well defined, their application is not necessarily easy or reproducible. ${ }^{54} 55$ 
Box 7: Special features in hysterectomy specimens for endometrial cancer

- Exact location: anterior or posterior myometrium, fundus, straddling the lower uterine segment/upper endocervical canal, left or right hand side, originating in the cornua, manner of growth (eg, polypoid, solid)

- Size: superior-inferior, anterior-posterior, left to right

- Blocks should include the lower segment, cornua and all three planes to define distance to the serosa

- Type, grade (FIGO grade for endometrioid carcinoma; NB squamous areas are not included in this grading system; nuclear grading for poor prognosis type disease)

- Presence of haemorrhage/necrosis

- Edge well defined, infiltrative, associated adenomyosis

- Lymphovascular invasion

- Background endometrium

- Depth of maximum extension into the myometrium and the minimal depth of myometrium unaffected by tumour (ie, is tumour confined to the inner or outer half of the myometrium); serosal involvement

- Extension of tumour into the lower uterine segment/cervical epithelium and stroma

- Adnexa, as above

- Associated hormone-producing lesions, such as thecomas

- Associated carcinomas (eg, of ovary)

- Immunophenotype: oestrogen receptor, progesterone receptor, p53

- Pending a formal internationally agreed system, endometrial stromal sarcomas and leiomyosarcomas if confined to the uterus are in practice cut like hysterectomy specimens for epithelial malignancies and similar staging information provided

As a minimum, a full thickness block of each lip of the cervix should be submitted and if there is tumour in the canal, entrapped in mucus or adherent to the surface the entire canal should be sampled (fig 16, a). ${ }^{56}$ I block the entire canal up front as it saves time, and I cut levels if there is any uncertainty as to the involvement of stroma. In addition, I take a block across the junction of the lower uterine segment and upper endocervical canal since tumour extension into the cervix upstages the tumour to FIGO stage 2 (fig 16, b). These blocks may have to be divided into two or more pieces to ensure they fit in the processing cassette.

There is currently some debate in the UK as to how endometrial tumours should be sampled. The traditional practice has been to cut serial slices in the sagittal plane (fig 16, c), select that with the greatest depth of tumour infiltration macroscopically, and submit the entire slice. In its minimum data set The Royal College of Pathologists ${ }^{57}$ has advocated sectioning in the "coronal plane". Although there is research to suggest that examination of whole mount transverse sections allows the depth of penetration to be most readily visualised, ${ }^{58}$ the President of the British Association of Gynaecological Pathologists has written to the President of The Royal College of Pathologists recommending that future editions of the college's document revert to the sagittal system (T P Rollason, personal communication, 2007). I suspect that the key point is to remember that the uterus is a threedimensional organ, and that since the uterine wall can be invaded in any on those planes, a technique that examines them

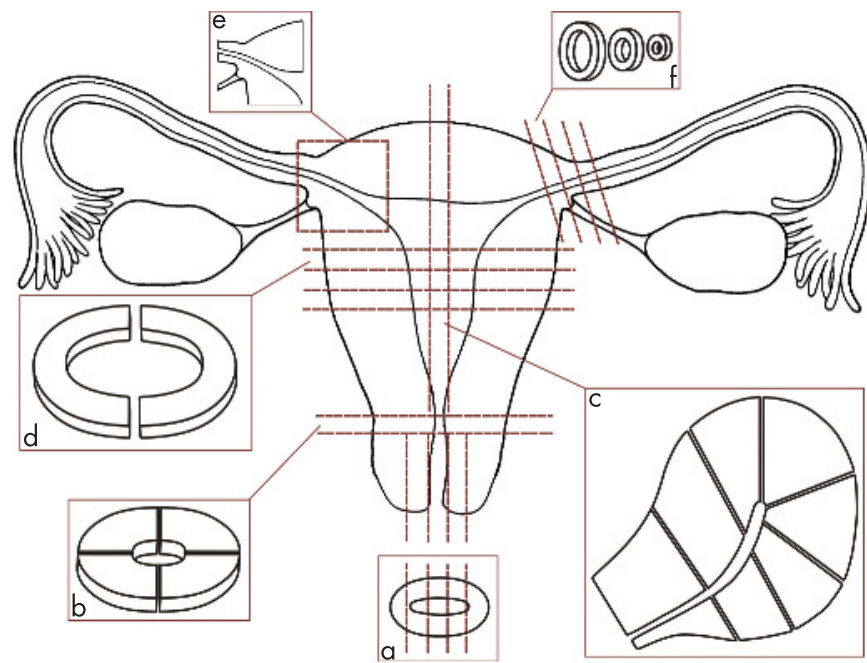

Figure 16 Diagram showing blocking system for "malignant" uterus.

all is required. My own practice is to follow the traditional method, but once the cavity begins to peter out (fig 16, d), I rotate the specimen and make transverse sections. I take transverse blocks for histological assessment at the point at which tumour infiltrates most deeply into the left and right lateral myometrium (fig 16, d), since in $13.9 \%$ (95\% CI $8.4 \%$ to $21.9 \%$ ) cases the right, left or both lateral myometrial blocks have been found to have been invaded.

There is also debate as to the best method of examining the cornua. I prefer to cut in an essentially coronal plane as I feel it allows me to inspect the surface of the endometrium out as far as the isthmus of the tube, and reassure myself as to its involvement (fig 16, e). The myometrium anterior and posterior to the endometrium-myometrium junction can then be trimmed back so the specimen can be examined in a standard processing cassette. Others prefer to take transverse sections across the tube at its insertion, moving proximally and progressively sampling more of the junction of endometrium and myometrium (fig 16f). I feel this method removes the opportunity for a thorough visual inspection of the cornual endometrium and reproduces information available in the sections taken from the proximal Fallopian tube that will be sampled in any case, but would concede that from the point of view of staging tumours, there is probably little between the two techniques and it is a matter of choice.

I found that in 29 of 101 cases ( $28.7 \%, 95 \%$ CI $20.8 \%$ to $38.2 \%$ ) one or other or both cornua were involved. Although these blocks occasionally revealed a greater proportion of myometrium infiltrated by tumour than in the corpus, in no case $(0 \%, 95 \%$ CI $0 \%$ to $3.7 \%$ ) did it alter the stage of the tumour.

Fallopian tubes, ovaries and lymph nodes are sampled as described above.

Endometrial tumours are typed according to the WHO classification, ${ }^{31}$ but this is not exhaustive and distinct entities have since been introduced into practice. The tumours are staged according to the method of the International Union Against Cancer $^{1}$; this also provides a two-stage system for grading endometrioid carcinomas based on an appraisal of architectural appearance and nuclear grade. The assessment of the architectural grade requires an assessment of the tumour that has a solid non-glandular configuration EXCLUDING the squamous areas; this is not an easy thing to do, but one can draw some comfort from the findings of a morphometric study 
that suggested that the extent of solid areas in all grades of endometrial cancer are directly related to prognosis, suggesting that there may be some margin of error in favour of over-calling solid areas. ${ }^{59}$ The assessment of nuclear features defines grade 1 and 3 nuclei quite clearly, but simply describes grade 2 nuclei as having features between the two. Not surprisingly the two grading components are only moderately reproducible $(k=0.49$ architectural grade, $\mathrm{k}=0.57$ nuclear grade). ${ }^{60}$

If there is a second type of tumour present, I prefer to record its presence and give an estimate of the overall proportion of tumour it comprises rather than making a diagnosis of mixed tumour only if a minimum proportion is exceeded. The criteria used for such classifications may vary and this avoids the need for reviewing large numbers of cases should this occur.

The report should include details of the background endometrium and in particular if it is atrophic as opposed to showing features of endometrial hyperplasia.

The depth of invasion into the myometrium should be confirmed histologically, although the macroscopic assessment provides the same staging information in most cases, ${ }^{61}{ }_{62}$ providing the case does not include foci of adenomyosis colonised by cancer. A recent cohort study has suggested that involvement of adenomyosis by endometrioid carcinoma is associated with an increased risk of myometrial invasion and of stage $1 \mathrm{c}$ disease in FIGO grade 1 carcinoma, ${ }^{63}$ although earlier smaller studies have suggested that this is not associated with a worse prognosis. ${ }^{64}{ }^{65}$ The presence of vascular invasion is also determined, although care must be taken to ensure this feature is not over-reported due to artefact..$^{52} 66$

The alternative bivalve method of examining the uterus, widely used in North America, consists of incising the lateral walls of the uterus with a pair of scissors. ${ }^{3}$ This allows serial sections to be made through the endometrium and myometrium so that the maximum depth of any tumour can be assessed facilitating sampling for frozen section. I have very limited experience of this method and, aside from the difficulties in opening a thick-walled muscular organ with scissors, I am concerned about the distortion of the relatively thin slices of fresh tissue during fixation, although pathologists who use the technique have reassured me that this is not a problem in their hands (R E Scully, personal communication, 2007).

Peritoneal washings may have been submitted.

\section{Hysterectomy for hyperplasia}

Two full-thickness blocks from each of the anterior and posterior walls of the uterus, including endometrium, myometrium and serosa, are taken, and if necessary they are divided into two or more pieces so that they fit into the processing cassette. $^{46}$ If in the text of the report of the preceding endometrial sample there is any concern about invasive disease, more extensive sampling may be advisable as over half of such cases are later shown to harbour an invasive malignancy. ${ }^{28}{ }^{67}$ As with frank cancers, I also take blocks from across the junction of lower segment/upper canal and the cornua.

\section{Hysterectomy following TCRE}

These are largely dealt with as above, but a specific note as to the presence of cervical stenosis, endometrial synechiae, necrotic material and how much of endometrial cavity is obliterated should be made. I essentially block these cases in the same way as I do hyperplasias, not because I am concerned about premalignant disease, but to ensure a good sampling of the cavity, as only small foci of endometrium may remain, but they may account for the symptoms that explain the failed procedure.

\section{Hysterectomy for CIN/dyskaryosis}

Hysterectomy specimens obtained from a woman with an abnormal smear ${ }^{6}$ may harbour high-grade CIN and even invasive lesions. Because of the risk of an occult cancer, it is desirable to evaluate an intervening cone biopsy or loop excision to exclude these conditions so that in the case of carcinoma the need for lymph node sampling and more extensive local surgery can be determined. ${ }^{68}$

If the cervix contains a CIN lesion, whether or not it was suspected before operation, it has traditionally been blocked out in its entirety. ${ }^{69}{ }^{70}$ It is best also to take a block across the upper end of the cervix, as there is a risk of CIN being displaced upward during the healing process that follows a large loop excision of the transformation zone (fig 16, $a$ and $b$ ).

A less extensive sampling procedure has been advocated in patients with a history of a CIN lesion if intervening smears or biopsies are negative, ${ }^{71}$ and a previous small study would seem to provide some support for limiting the examination to sections that demonstrate the epithelium lining the canal and lower segment. ${ }^{68}$

The report should include details of the grade, extent and involvement of margins in the same way as in a loop or cone biopsy. If there is completely excised CIN, further smears should be taken at 6 and 18 months. If the CIN is incompletely excised, the woman is followed up as if the cervix were in situ. ${ }^{72}$

\section{Hysterectomy for carcinoma of the cervix}

If the hysterectomy is for carcinoma of the cervix, it is necessary to describe its site, dimensions, appearance and the macroscopic extent of infiltration, as listed in box 8 . A record should be made

\section{Box 8: Special features in hysterectomy specimens for} cervical cancer

- Vaginal cuff: absent/present (measurement of length)

- Shape of cervix: normal, barrel shaped, polyps

- Site: ecto or endocervical, anterior or posterior, left or right

- Size

- Appearance

- Polypoid, papillary, nodular, solid, ulcerating

- Macroscopic extent of infiltration into cervical wall, parametria, endometrium, myometrium, vagina

- Presence or absence of previous site of cone biopsy

The report should include the following:

- Tumour

- Size: in three dimensions, (FIGO stage $1 \mathrm{~A} 1$ is defined as measuring $7 \times 7 \mathrm{~mm}$ laterally $\times 3 \mathrm{~mm}$ deep)

- Type: rare types include basaloid, lymphepithelioma-like, minimal deviation, glassy cell, adenoid basal, mucoepidermoid, adenoid cystic

- Grade

- Lymphovascular invasion

- Associated intraepithelial disease squamous and glandular, and consider intraepithelial neoplasia at other sites in the genital tract

- Invasion of adjacent structures: vagina, paracervical fat, myometrium, etc

- Distance to lateral and vaginal margins if microscopically assessable 
of the presence of any loop or cone biopsy site to avoid confusion later.

If a vaginal cuff is submitted it may be necessary to trim it circumferentially in order to visualise and assess the surface of the cervix and to allow it to be photographed. This should all be embedded, as it represents the vaginal resection margin. If only a short length of vaginal cuff is submitted this will not be necessary, and the vaginal resection margin should be assessed perpendicularly in continuity with the cervix.

The cervix is cut into transverse slices in the same way as a loop biopsy and it is all submitted, along with any paracervical tissue (fig 16, a). The location of the origin of each block is made on the photograph. Full transverse sections from the uterus immediately above the cervix are taken to detect upward extension (fig 16, b). Although this does not alter pathological staging, the healing that follows cone or loop biopsy may result in the tumour being displaced up the canal, and I have found on occasion that these may be the only blocks containing residual tumour or they may be the site of its maximum depth of invasion.

The absence of involved edges in the preceding loop does not exclude the possibility of residual tumour in the hysterectomy specimens, and this may result in the tumour being upstaged. ${ }^{73}$

Additional features to include are listed in box 8 . The distance to the nearest resection margin should be measured histologically if possible and the report should specify which this is some surgeons specifically request this information for both left and right lateral limits. This is achieved by counting the number of uninvolved slices on either side of the tumour and multiplying by three (or whatever the average thickness of these is judged to be) to give the distance in millimetres.

\section{Box 9: Special features in Fallopian tube specimens}

- Weight: not necessary if removed incidentally or for sterilisation

- Measure: length and maximum diameter

- Dilation of the lumen is noted

- Presence/absence of fimbriae, inversion of fimbriae

- Number and site of previous interruptions, presence of clips or rings

- Presence/absence of paratubal cysts

- Site (cornual, isthmic, infundibular, ampullary) size and relationship to the lumen or serosa of any lesion or mass

- Condition of the wall of the tube: thickened? dilated?

- Patency of tubal lumen, dilation, contents, plical fusion may be visible macroscopically; in particular the presence of haemorrhage, placental tissue, placental sac or fetus should be recorded and sampled for histology

- State of mucosa: atrophic? thickened?

- Serosa: adhesions, exudate, attachment to adjacent organs, rupture with protrusion of contents through the wall

- Separate samples of blood should be examined and sampled

- The report usually requires a comment on the presence of inflammation plical/fimbrial damage and the contents of the lumen of the tube

- Associated disease such as endometriosis, hyperplasia, in situ or invasive malignancy is also required. Contents of the lumen (if any), (eg, blood, placenta, gestational sac with/without fetus) should be recorded

\section{FALLOPIAN TUBE}

It is usually unnecessary to weigh Fallopian tubes removed incidentally or for sterilisation, but in all cases it is desirable to measure the length of the specimen and its maximum diameter. ${ }^{51}$ It is usually impossible to comment on laterality unless the tube is still attached to the uterus. The specimen should be serially sectioned at approximately $3 \mathrm{~mm}$ intervals throughout its length. Helpful surgeons sometimes open the tube longitudinally in theatre; however, this should be discouraged as it deprives the pathologist of the means of assessing the integrity of the serosa. Other features deserving assessment are listed in box 9. The mucosal plical pattern of the tube and the patency or dilatation of the tubal lumen should be visible on inspection of the cut surface of the tube.

Full-circumferential sections from isthmus and ampulla should be examined histologically, as these may give an indication of any pathology present before the event precipitating the operation. Any abnormalities (eg, ectopic gestational products) should be recorded, or if there is no evidence of an abnormality then the mid section should be sampled.

\section{Ectopic pregnancy}

These are essentially described as above, but when reporting a molar pregnancy in an ectopic gestation the pathologist should remember that the trophoblast can be unusually prominent at this site. This results in overdiagnosis of the condition so that only $6 \%$ of cases of tubal molar pregnancy have been confirmed as opposed to $90 \%$ of uterine molar pregnancies in the Charing Cross unit, which is one of a number of UK molar pregnancy reference centres. ${ }^{74}$

\section{Carcinoma}

Carcinoma of the tube is very rare, and the description should follow that described above, with particular attention being paid to any serosal breaches or other defects. It is defined by the WHO as being located within the tube or its fimbriated end on macroscopic examination, and not associated with another tumour in the female genital tract except those with a different phenotype. ${ }^{31}$ Full sections through the tube are examined to document the depth of invasion and presence of any serosal breach.

\section{Prophylactic salpingectomy}

In cases of prophylactic salpingectomy removed from patients with a perceived increased risk of adnexal neoplasia, such as a family history of adnexal cancer, with or without an accompanying oophorectomy, the fimbrial end should be amputated and sectioned longitudinally at $2-3 \mathrm{~mm}$ intervals. The remainder of the tube is sectioned at $2-3 \mathrm{~mm}$ intervals cross-section and all the tissue is embedded, since foci of neoplasia may be very tiny and are on occasion multifocal. ${ }^{75}$

\section{Post sterilisation}

A complete cross-section of the tube, including lumen, muscularis and preferably serosa, should be visualised before confirming interruption of the tube.

\section{Failed sterilisation}

It is usually best if samples originating from operations to reverse sterilisation or following a failed sterilisation are described, dissected and reported by medical staff of consultant status if only because having the person who dealt with the specimen in the department simplifies the process associated 
with any later legal action. At the very least it is desirable to specify how the specimen was described on the specimen request card to avoid any future confusion, and to photograph and then describe it (box 9), marking the site of origin of all the blocks on a photograph so that these can be consulted when reporting the case. The contents of any clips should be submitted in a separately identified cassette. After ensuring adequacy of orientation in the first section, I usually examine the tissue through multiple levels or serial sections looking for tubal patency or evidence of recanalisation (box 9).

\section{OVARIES REMOVED FOR NON-NEOPLASTIC CONDITIONS}

These should be weighed and all three dimensions measured. It is usually only possible to assess laterality if ovaries remain attached to the uterus. I do not usually ink the margins and I would not advocate ovaries being bivalved. The external surface is examined, and the presence of adhesions, nodules or other abnormalities is noted. The dimensions of the Fallopian tube (if present) are recorded, and any adhesions between the two are noted.

The specimen should be sliced at 3-4 $\mathrm{mm}$ intervals through the full thickness in the sagittal plane. The contents of any cysts (eg, thickened blood due to endometriosis) are recorded. At least two slices of ovary and Fallopian tube are submitted; if possible these should be in continuity to identify endometriosis in the intervening tissues, as described above.

Thick-walled cysts should be sampled at one block per $10 \mathrm{~mm}$ of the maximum diameter.

Prophylactic oophorectomy specimens from patients with familial ovarian cancer or relevant genetic abnormalities are examined in their entirety and if submitted fresh, tissue may be taken for frozen section or snap frozen for biochemical or genetic assays (box 10).

\section{Box 10: Special features of ovarian biopsy specimens}

- Type of biopsy (eg, wedge)

- Describe tissues included (eg, serosal epithelium, cortex, cysts if any, follicles)

- Presence of tumour within parenchyma or on serosal surface

- Dimensions (NB, tumours that are not confined to the serosal surface or which are $>5 \times 5 \mathrm{~mm}$ are by definition inconsistent with primary peritoneal carcinomas ${ }^{83}$

\section{OVARIES REMOVED FOR NEOPLASTIC DISEASE}

These should be weighed and measured. I do not usually ink the margins but find it helpful to paint the edges of any defects in the capsule, the site and size of which should be recorded. A checklist of features to look for is given in box 11 .

\section{Blocks: from where and how many?}

Conventional practice is to take at least one block per $10 \mathrm{~mm}$ of the maximum diameter of the tumour or cyst including any thin walled areas and return to take more blocks if there are suspicious features (eg, should the histology show florid proliferation). Some authors advocate more intensive blocking in large tumours ${ }^{76}$ to ensure that small foci of invasion are not overlooked, but the extent to which blocks are taken appears to be based in the diameter of the more solid or multicystic areas

\section{Box 11: Special features of ovary specimens}

\section{Handling at cut-up:}

- Weight and dimensions in three planes

- Laterality if this can be assessed with certainty

- External surface: smooth, adhesions, direct infiltration by tumour?

- Capsule: intact, ruptured? adhesions: inflammatory or neoplastic? haemorrhage, surface tumour/implants

- Cut section: presence of cysts, corpora lutea, calcification, haemorrhage, stromal nodules

- Cysts: single, multiple, (although every locule should be examined it is not necessary to measure or describe each one individually)

- Cyst contents: serous, mucoid, viscid, teeth, hair? in mature cysts: cystic teratoma-hair, sebum, Rokatansky's tubercles

- Inner surface of cyst: papillary areas, solid areas (dimensions), haemorrhage, necrosis, calcification, any solid masses present (size)

- Fallopian tube: length and width (if present)

Blocks should include:

- Solid/papillary areas

- Areas where the tumour comes close to the serosal surface

- Areas of direct infiltration by tumour

- Breaches in the capsule

- Adhesions

- Background normal ovary

- Fallopian tube ideally including the soft tissue between it and the ovarian tumour

Specific features to include in report:

- Tumour:

- Histological type (WHO classification)

- Benign, borderline (proliferative), malignant (if malignant is it a borderline tumour with microinvasion, microinvasive carcinomas ${ }^{77}$

- Invasive

- Histological grade

- Lymphovascular involvement

- Capsular infiltration and breach

- Serosa

- Background ovary: presence of cortex and features in it (eg, luteinisation, endometriosis)

- Fallopian tube

- Paratubal connective tissue

- Other ovary and Fallopian tube

- Uterus

- Lymph nodes: beware of overcalling endosalpingiosis

- Peritoneal biopsies: beware of confusing endosalpingiosis or implants with metastatic disease

- Appendix

and to exclude the thin-walled area of the cyst so that the two systems may result in similar numbers of blocks being examined in suspicious lesions. ${ }^{77}$ Each system results in only a minority of the tissue being examined histologically, and Ludwick et al ${ }^{78}$ calculated that even if an entire ovarian tumour were submitted as sections of $2 \mathrm{~mm}$ thickness, only $0.25 \%$ of the tumour would be examined histologically.

Blocks should be taken as listed in box 11, and the cassettes that contain features of interest should be identified on the 
block sheet or in the description. More than one portion of tissue may be fitted into a processing cassette. It is worth stressing the importance of blocking any areas where the capsule is breached or where infiltrative tumour extends through or close to the serosal surface. Blocks of the Fallopian tube including the soft tissue between it and the ovarian tumour provide the best opportunity of sampling residual ovary, ${ }^{46}$ or may be the site of metastases or direct tumour extension. Peri-adnexal tissues have been found to be involved in $20 \%$, (95\% CI 13.3\% to 28.9\%; mesosalpinx, $13 / 100(13 \%)$, $95 \%$ CI $7.8 \%$ to $21 \%$; mesovarium, $7 / 100$ (7\%), $95 \%$ CI $3.4 \%$ to $13.7 \%)$ of ovarian carcinomas. Six of 25 patients $(24 \%, 95 \%$ CI $11.5 \%$ to $43.4 \%$ ) with intact tumours had peri-adnexal spread and in one $(1 \%, 95 \%$ CI $0.2 \%$ to $5.4 \%)$ this was the only evidence of spread outside the ovary.

It is also desirable to sample the uterine serosa to demonstrate serosal deposits, which may be synchronous tumour or metastatic/trans coelomic spread. The posterior uterine reflection has been found to be involved in six of 89 cases $(6.7 \%, 95 \%$ CI $3.1 \%$ to $13.9 \%$ ), while the left and right cornua blocked to show peritoneal reflections were involved in 28 of 89 cases (31.5\%, 95\% CI $22.8 \%$ to $41.7 \%$ )

If the appendix has been submitted as part of the surgical procedure it should be sampled in its entirety to exclude it as a site of origin of a metastasis to the ovary.

\section{Tumour}

Although traditionally the tumour is typed based on the predominant pattern, and only described as mixed if a minority component represents $10 \%$ or more of the total volume, I prefer to list all the histological types present using the WHO classification and give an estimate of the proportion of the tumour that each provides.

To date there is no universally agreed grading system for ovarian cancer except for ovarian endometrioid carcinoma, which is graded using the same system as for endometrial endometrioid tumours. Traditionally the histological grade has been ascribed using a simple three-grade system (well, moderate and poor), although there have been recent efforts to produce a grading system that provides a better prediction of tumour behaviour and response to medication. ${ }^{79}$ It is still necessary to type these tumours if possible, as this also gives an indication of tumour behaviour. In cases of interval debulking surgery, it should be recalled that preoperative chemotherapy may so alter the morphology of ovarian or disseminated tumours as to make their grading and even typing unreliable. ${ }^{80}$

The current staging system for ovarian carcinoma has been critically appraised. ${ }^{81}$ The points that need to be included in the histological assessment of the extent of the tumour to achieve this are listed in box 11.

When an endometrioid tumour is encountered in both endometrium and ovary, clinicians often ask whether they are independent primaries or if one is the metastasis of the other. Recent molecular data suggest traditional methods of distinguishing between them are robust. ${ }^{82} 83$

\section{Frozen section}

There is a suggestion that intraoperative frozen section may be beneficial by providing the diagnosis in ovarian cystic lesions, and thus allowing the extent of the operation to be tailored for staging and therapeutic purposes. It is difficult to know what the evidence base for this statement is, since most large series report discrepancies between the frozen section diagnosis and the final paraffin diagnosis, particularly in the key areas of borderline versus malignant and to a lesser extent borderline versus benign ( $\mathrm{P}$ Cross, personal communication, 2007). ${ }^{84} 85$ Indeed pathologists may deliberately over stress the possibility of undetected invasion ${ }^{84}$ to ensure patients receive omentectomy during the primary procedure..$^{53}$ My personal view is that most cases of benign and malignant ovarian disease are obvious even on cursory macroscopic diagnosis of the intact specimen. Once such cases are excluded from the analyses, frozen section is at least as likely to get the diagnosis wrong as right. Given therefore that it is as likely to mislead the surgeon as to guide him in deciding which operation is required, and that performing the intraoperative consult compromises the specimen for final histological diagnosis, the pathologist is justified in deterring the use of this technique. This should provoke investigation of more robust diagnostic and therapeutic strategies (box 11).

\section{Primary peritoneal carcinoma}

Primary peritoneal carcinoma may be diagnosed if the ovary is normal or affected only by benign ovarian disease. It may still be diagnosed if the extraovarian malignancy is greater than that in the ovary, and the ovarian malignancy is confined to the surface epithelium, and is less than $5 \times 5 \mathrm{~mm}$ whether present on the surface or confined to the parenchyma. If the patient had an ovary removed within the preceding 5 years, the slides should be reviewed and, if more than 5 years ago, a copy of the report obtained to ensure there was no evidence of cancer at that time. ${ }^{8386}$

\section{OMENTECTOMY INCLUDING THOSE FOR STAGING OF OVARIAN CARCINOMA}

The specimen is weighed and measured in three dimensions. The presence or absence of any macroscopic abnormality is recorded and their maximum dimension noted.

The omentum is sliced at $5 \mathrm{~mm}$ intervals and representative samples of macroscopically visible tumour are taken. If the omentum is unaffected by macroscopic tumour or inflammation this may be facilitated by rolling it into a "Swiss roll". A recent study suggests that in borderline tumours it is sufficient to sample any areas of thickening that may be present since further blocks are uninformative. ${ }^{88}$ If no tumour is visible, I take six representative blocks.

\section{PERITONEAL AND POUCH OF DOUGLAS BIOPSIES, INCLUDING THOSE FOR THE STAGING OF OVARIAN CARCINOMA}

I weigh the specimen if it is bulky, but in all cases I count the number of fragments and note the maximum dimension of the largest piece. As for the omentum, I note the presence or absence of any macroscopic tumour deposits or other abnormalities. All of the tissue is embedded unless it is large and obvious tumour is present in which case representative samples suffice. I do not tend to level these specimens up front, as if there is tumour I like to preserve material in case immunohistochemical or other studies are needed. With peritoneal biopsies from the benign gynaecological service, as opposed to gynaecological oncology, I would not ask for levels if I knew that the case had been performed by an experienced laparoscopist, who was satisfied that only benign pathology was present.

A comprehensive account of the use of special techniques in the reporting of ovarian specimens and their associated samples is available in a standard textbook ${ }^{87}$ 


\section{COMPUTER-GENERATED TEXT IN PATHOLOGY REPORTING}

Like many pathologists I have used short series of text, which the computer automatically expands to create a larger portion of text, for some years. I tend not to use these when describing specimens consisting of malignant tumours except if including such routine negatives as the absence of vascular invasion. I have also learned to avoid using short texts that are too similar to each other to avoid confusing them and generating a report with a substantially different text to the one I intended.

Acknowledgements: Mr Michael Todd for preparing the photographs and figures; Drs S Knight, S Osborne and A Barr for reading the manuscript; the staff of the medical library at the University of Leeds for providing publications; Mr S Bradburn and Mr N Dickenson for helping with data manipulation.

Competing interests: None.

\section{REFERENCES}

1. Sobin LH, Wittekind Ch, eds. TNM classification of malignant tumours (UICC). 6th edn. New York: Wiley-Liss, 2002

2. Robboy SJ, Noller KL, O'Brien $P$, et al. Increased incidence of cervical and vaginal dysplasia in 3980 diethylstilbestreol-exposed young women. JAMA 1984:252:2979-83.

3. Robboy SJ, Kraus FT, Kurman RJ. Gross description, processing and reporting of gynecological and obstetric specimens. In: Kurman RJ, ed. Blausteins' pathology of the female genital tract. 5th edn. New York: Springer, 2002:1326.

4. Scully RE, (in collaboration with pathologists from 10 countries). Histological typing of female tract tumours. 2nd edn. Berlin: Springer-Verlag, 1994:68.

5. Heatley $\mathbf{M}$. A comparison of three methods of orientating cervical punch biopsies. $J$ Clin Pathol 1999:52:149-50.

6. National Health Service Cervical Screening Publications. Histopathology reporting in cervical screening. Working party of the Royal College of Pathologists and the NHS cervical screening programme. NHSCSP no. 10. London: NHSCSP, 1999.

7. Heatley MK. How many histological levels should be examined from tissue blocks originating in cone biopsy and large loop excision of the transformation specimens of the cervix. J Clin Pathol 2001:54:650-1.

8. Cardoza-Favarato G, Fadare 0 . High grade cervical intraepithelial neoplasia excised with negative margins by loop electrosurgical procedure. The significance of grade 1 CIN at the margins of excision. Lab Invest 2007;87(Suppl 1):191A.

9. Demopoulos RI, Horowitz LF, Vamvaka EC. Endocervical gland involvement by cervical intraepithelial neoplasia grade III. Cancer 1991;68:1932-6.

10. Dietrich CS, Yancey MK, Miyazawa K, et al. Risk factors for early cytological abnormalities after loop electrosurgical excision procedure. Obstet Gynecol 2002,99:188-92.

11. Novotny DB. Predictors of recurrent dysplasia after cervical loop electrocautery excision for CIN-3. Mod Pathol 1999:12:233-8.

12. Zaitoun AM, McKee G, Coppen MJ, et al. Completeness of excision and follow up in patients treated with loop excision biopsy. J Clin Pathol 2000:53:191-6.

13. Kierkegaard 0, Byrjalsen C, Hansen KC, et al. Association between colposcopic findings and histology in cervical lesions: The significance of the size of the lesion. Gynecol Oncol 1995;57:66-71.

14. Tidbury $\mathbf{P}$, Singer A, Jenkins D. CIN3: the role of lesion size in invasion. Br J Obstet Gynecol 1992;99:583-6.

15. Kirkham N, Cotton D. Measuring melanomas, the Vernier method. J Clin Pathol 1984,37:229-30

16. Haas J. Tumormetric measurements and morphometry in cervical cancer. Ballieres Clin Obstet Gynaecol 1988;2:781-7

17. Burghardt $\mathbf{E}$, Girardi F, Lahousen $\mathbf{M}$, et al. Microinvasive carcinoma of the uterine cervix (International Federation of Gynecology and Obstetrics Stage IA). Cancer 1991;67:1037-45.

18. Association of Directors of Anatomic and Surgical Pathology Recommendations for the reporting of surgical specimens containing uterine cervical neoplasms. Am J Clin Pathol 2000;114:847-51.

19. Greer BE, Figge DC, Tamimi HK, et al. Stage 1 A2 squamous carcinoma of the cervix: difficult diagnosis and therapeutic dilemma. Am J Obstet Gynecol 1990;162:1406-11.

20. Anderson MC. Female reproductive system. In: Systematic pathology. 3rd edn. Edinburgh: Churchill Livingstone, 1991

21. Hellen EA, Coghill SB, Shaxted EJ. Histopathology of transcervical resection of the endometrium. Histopathology 1993;22:361-6.

22. Valle RF, Baggish MS. Endometrial carcinoma after endometrial ablation. High risk factors predicting its occurrence. Am J Obstet Gynecol 1998;179:569-72.

23. Vilos GA, Harding PG, Silcox JA, et al. Endometrial adenocarcinoma encountered at the time of endometrial ablation. J Am Assoc Gynecol Laporosc 2002;9:40-8.

24. Dwyer NA, Stirrat GM. Early endometrial carcinoma: an incidental finding after endometrial resection. Case report. Br J Obstet Gynaecol 1991;98:733-4.

25. Perez-Medina T, Bajo-Arenas J, Sanfrutos L, et al. Endometrial intraepithelial neoplasia diagnosed at endometrial resection. J Am Assoc Gynecol Laporosc 2003;10:542-4.

26. Buckley CH, Fox H. Biopsy pathology of the endometrium. 2nd edn. London: Arnold, 2002:4-5
27. Hecht JL, Ince TA, Baak JPA, et al. Prediction of endometrial carcinoma by subjective endometrial intraepithelial neoplasia diagnosis. Mod Pathol 2005;18:32430.

28. Shutter J, Wright TC. Prevalence of underlying adenocarcinoma in women with atypical endometrial hyperplasia. Int J Gynecol Pathol 2005;24:313-8.

29. Mitchard J, Hirschowitz L. Concordance of FIGO grade of endometrial adenocarcinomas in biopsy and hysterectomy specimens. Histopathology 2003; 42:372-8.

30. Creasman WT. FIGO stages, 1988 revision. Gynecol Oncol 1989;35:125-7.

31. Tavisolli F, Develli P. World Health Organization classification of tumours: tumours of the female genital organs. Lyon: IARC Press, 2003.

32. Dubinsky TJ, Parvey HR, Maklad N. The role of transvaginal sonography and endometrial biopsy in the evaluation of peri- and postmenopausal bleeding. AJR 1997; 169:145-9.

33. Tabor A, Watt HC, Wald NJ. Endometrial thickness as a test for endometrial cance in women with postmenopausal vaginal bleeding. Obstet Gynecol 2002;99:663-70.

34. Feldman S, Shapter A, Welch WR, et al. Two year follow-up of 263 patients with post/perimenopausal vaginal bleeding and negative initial biopsy. Gynecol Oncol 1994:55:56-9.

35. Lindgren R, Mattsson LA, Andersson K, et al. Transvaginal ultrasonography and endometrial histology in peri- and postmenopausal women on hormone replacement therapy. Br J Obstet Gynaecol 1999;106:421-6.

36. Van den Bosch T, Vandendael A, Van Schoubroeck D, et al. Combining vaginal ultrasonography and office endometrial sampling in the diagnosis of endometrial disease in postmenopausal women. Obstet Gynecol 1995;85:349-52.

37. Danero S, Ricci MG, La Rosa $\mathrm{R}$, et al. Critical review of dilatations and curettage in the diagnosis of malignant pathology of the endometrium. Eur J Gynaec Oncol 1986; 7:162-5.

38. Stock RJ, Kanbour A. Prehysterectomy curettage. Obstet Gynecol 1975;45:537-41.

39. Eckert LO, Hawes SE, Wolner-Hanssen PK, et al. Endometritis: the clinicalpathologic syndrome. Am J Obstet Gynecol 2002;186:690-5.

40. Siddiqui MA, Lieberman RW. Spindle cell alteration of endometrial stroma as a predictor of plasma cell infiltration. Abstract no. 910. Mod Pathol 2006; (Suppl 1):196A

41. Bakour SH, Khan KS, Gupta JK. The risk of premalignant and malignant pathology in endometrial polyps. Acta Obstet Gynecol Scand 2000;79:317-20.

42. Martin- Ondarza C, Gil-Moreno A, Torres-Cuesta L, et al. Endometrial cancer in polyps: A clinical study of 27 cases. Eur J Gynaec Oncol 2005;26:55-8.

43. Hietto D, Fadare 0, Martel M, et al. Endometrial polyp associated with increased risk of cancer involvement in postmenopausal women. World J Surg Oncol 2005;3:8.

44. da Costa D, Mittal K. Endometrial hyperplasia in endometrial polyps: clinicopathologic and follow-up findings. Mod Pathol 2006;19(Suppl 1):175A

45. McCluggage WG. My approach to the interpretation of endometrial biopsies and curettings. J Clin Pathol 2006;59:801-12.

46. Robboy SJ, Kraus FT, Kurman RJ. Gross description, processing and reporting of gynecological and obstetric specimens. In: Kurman RJ, ed. Blaustein's pathology of the female genital tract. 5th edn. New York: Springer, 2002:1330.

47. Salmon HA, Smith JHF, Balsitis M. Is microscopic assessment of macroscopically normal hysterectomy specimens necessary? J Clin Pathol 2002;55:67-8.

48. Houghton JP, Roddy S, Carroll S, et al. A simple method for the prevention of endometrial autolysis in hysterectomy specimens. J Clin Pathol 2004;57:332-3.

49. Heatley MK. A critical evaluation of the use of the Schiller test in selecting blocks taken from the uterine cervix in suspected intraepithelial neoplasia. Ulster Med 1995;64:147-50.

50. Heatley MK. The value of Polaroid photography in reporting cervical cone and large loop excision specimens. J Cellular Pathol 2000;5:7-10.

51. Kim SH, Shin CJ, Kim JG, et al. Microsurgical reversal of tubal sterilization : a report on 1118 cases. Fertil Steril 1997:68:865-70.

52. Ali-Fehmi R, Arabi MH, Morris RT, et al. Should intraoperative frozen section diagnosis be used to determine surgical staging for patients with endometrial carcinoma. Lab Invest 2007:87(Suppl 1):187A

53. Ismiil N, Nofech-Mozes S, Ghorab Z, et al. Intraoperative reporting of ovarian tumors with borderline features. Lab Invest 2007:87(Suppl 1):187A.

54. Ali AS, Soslow RA. Discrepancies in assessing depth of invasion in endometrial carcinoma. Mod Pathol 2005;18(Suppl 1):176A.

55. Zaino RJ. Endometrial hyperplasia and adenocarcinoma. In: Fox H, Wells M, eds. Haines and Taylor obstetrical and gynaecological pathology. 5th edn. London: Churchill Livingstone, 2002:474-5

56. Jordan LB, Al-Nafussi A. Clinicopathological study of the pattern and significance of cervical involvement in cases of endometrial adenocarcinoma. Int $\mathrm{J}$ Gynecol Cancer 2002;12:42-8.

57. The Royal College of Pathologists. Standards and minimum data sets for reporting cancers. Minimum dataset for the histopathological reporting of atypical hyperplasia and adenocarcinoma in endometrial biopsy and curettage specimens and for endometrial cancer in hysterectomy specimens. London: The Royal College of Pathologists, 2001.

58. Templeton AC. Reporting of myometrial invasion by endometrial cancer Histopathology 1982:6:733-7.

59. Alm P, Gudmundsson T, Martensson R, et al. Identification of small solid growth has a strong prognostic impact in differential endometrial carcinomas. Int J Gynecol Cancer 1995:5:87-93. 
60. Zaino RJ, Silverberg SG, Norris HJ, et al. The prognostic value of nuclear versus architectural grading in endometrial adenocarcinoma: A gynecologic Oncology Group study. Int J Gynecol Pathol 1994;13:29-36.

61. Heatley MK. Cancer of the corpus uteri, appendix 1: pathology. In: Benedit JL, Hacker NF, Ngan HYS, eds. Staging classifications and clinical practice guidelines of gynaecological cancers. London: International Federation of Gynecology and Obstetrics (FIGO), 2000:59-80.

62. Spiegel G. The reliability of intraoperative consultations in assessing depth of invasion, subtypes and grades of endometrial carcinoma. Mod Pathol 2006;19 (Suppl 3):103A

63. Ismiil N, Rasty G, Ghorab Z, et al. Adenomyosis involved by endometrial carcinoma is a significant risk factor for deep myometrial invasion. Mod Pathol 2006;19 (Suppl 1):182A

64. Hall JB, Young $\mathrm{RH}$, Nelson JH. The prognostic significance of adenomyosis in endometrial carcinoma. Gynecol Oncol 1984;17:32-40.

65. Mittal KR, Barwick KW. Endometrial adenocarcinoma involving adenomyosis with out true myometrial invasion is characterized by frequent preceding estrogen therapy, low histologic grades and excellent prognosis. Gynecol Oncol 1993;49:197-201.

66. Herdman AV, Moller KA, Logani S. Vascular pseudoinvasion in laparoscopic hysterectomy specimens: a diagnostic pitfall. Lab Invest 2007;87(Suppl 1):200A

67. Horn L-C, Schnurrbusch U, Bilek K, et al. Risk of progression in complex and atypical endometrial hyperplasia: clinicopathological analysis in cases with and without progestogen treatment. Int J Gynecol Cancer 2004;14:348-53.

68. Greene A, Heatley MK. The appropriateness of examining the entire cervix histologically in hysterectomy specimens from women with a previous history of cervical intraepithelial neoplasia or dyskariosis. J Clin Pathol 2001;54:155-7.

69. Gurgel MSC, Bedone AJ, de Angelo Andrade LAL, et al. Microinvasive carcinoma of the uterine cervix: histological findings on cone specimens related to residual neoplasia on hysterectomy. Gynecol Oncol 1997;65:437-40.

70. Schorge J0, Lee KR, Flynn CE, et al. Stage 1A1 cervical carcinoma: definition and treatment. Obstet Gynecol 1999;93:219-22.

71. Anderson MC. Premalignant and malignant squamous lesions in the cervix. In: Fox $\mathrm{H}$, Wells M, eds. Haines and Taylor obstetrical and gynaecological pathology. Edinburgh: Churchill Livingstone, 1995:323-43.

72. National Health Service Cervical Screening Publications. In: Leusley D, Leeson S, eds. Colposcopy and programme management. Guidelines for the NHS cervical screening programme. NHSCSP no. 20. London: NHSCSP, 2004
73. Heatley MK. The presence of residual disease in the cervix of hysterectomy specimens from women in whom there has been a previous diagnosis of cervical carcinoma. J Obstet Gynaecol 2002;22:45-7.

74. Sebire NJ, Lindsay I, Fisher RA, et al. Overdiagnosis of complete and partial hydatidiform mole in tubal ectopic pregnancies. Int J Gynecol Pathol 2005;24:260-4.

75. Jarboe EA, Hirsch M, Crum CP, et al. Evidence supporting the fimbria as one site of origin for concurrent ovarian and endometrial carcinomas. Lab Invest 2007:87/Suppl 1):202A.

76. Seidman JD, Ronnett BM, Kurman RJ. Evolution of the concept and terminology of borderline ovarian tumours. Curr Diagn Pathol 2000;6:31-7.

77. Silverberg SG, Bell DA, Kurman RJ, et al. Borderline ovarian tumours: key points and workshop summary. Hum Pathol 2004;35:910-7.

78. Ludwick C, Gilks CB, Miller D, et al. Aggressive behavior of stage I ovarian mucinous tumors lacking extensive infiltrative invasion: a report of four cases and review of the literature. Int J Gynecol Pathol 2005;24:205-17.

79. Silverberg SG. Histopathologic grading of ovarian cancer: a review and proposal. Int J Gynecol Pathol 2000;9:7-15.

80. McCluggage WG, Lyness RW, Atkinson RJ, et al. Morphological effects of chemotherapy on ovarian carcinoma. J Clin Pathol 2002;55:27-31.

81. Manczer $\mathbf{J}$. Reflections of the FIGO surgical staging system of invasive epithelial ovarian cancer. Eur J Gynaecol Oncol 2003:24:215-22.

82. Kapali M, Dacia S, Esposito N, et al. Molecular analysis of simultaneous adenocarcinomas of the ovary and endometrium. Lab Invest 2007:87(Suppl 1):203A.

83. Scully RE, Young RH, Clement PB. AFIP Atlas of tumor pathology: tumors of the ovary, maldeveloped gonads, Fallopian tube, and broad ligament. Bethesda: American Registry of Pathology, 1998:126.

84. Boriboonhirunsarn D, Sermboon A Accuracy of frozen section in the diagnosis of malignant ovarian tumour. J Obstet Gynaecol Res 2004;30:394-9.

85. Stewart CJR, Brennan BA, Hammond IG, et al. Intraoperative assessment of ovarian tumours: a 5-year review with assessment of discrepant diagnostic cases. Int J Gynecol Pathol 2006;25:216-22.

86. Bloss JD, Liao S, Buller RE. Extraovarian peritoneal serous papillary carcinoma: a case control retrospective comparison to papillary adenocarcinoma of the ovary. Gynecol Oncol 1993:50:347-51.

87. Russell $\mathbf{P}$, Farnsworth A. Examination of the ovarian specimen. In: Russell $\mathbf{P}$, Farnsworth A, eds. Surgical pathology of the ovaries. 2nd edn. New York: Churchill Livingstone, 1997:25-37.

88. Allen C, Lele SM. Sampling of the grossly negative omentum in ovarian neoplasms Lab Invest 2007;87(Suppl 1):187A.

\section{Invitation to submit images for consideration as a Cover}

Readers are invited to submit images for consideration as a Cover. Cover images are not necessarily linked to a specific paper in that issue but rather are selected for their scientific/clinical interest and aesthetic appeal. We ask that readers only submit those images for which they hold the copyright. Colour images are preferred, should be a minimum of $600 \mathrm{dpi}$ and in CMYK mode. Please submit your images to jclinpath@bmjgroup.com in the first instance. Please also include a clear and concise legend explaining the image. All images will be credited to the appropriate supplier. 